\title{
Lightning search algorithm: a comprehensive survey
}

\author{
Laith Abualigah ${ }^{1}$ (I) - Mohamed Abd Elaziz ${ }^{2,3} \cdot$ Abdelazim G. Hussien $^{4} \cdot$ Bisan Alsalibi $^{5}$. \\ Seyed Mohammad Jafar Jalali ${ }^{6}$. Amir H. Gandomi ${ }^{7}$
}

Accepted: 12 September 2020 / Published online: 3 November 2020

(C) Springer Science+Business Media, LLC, part of Springer Nature 2020

\begin{abstract}
The lightning search algorithm (LSA) is a novel meta-heuristic optimization method, which is proposed in 2015 to solve constraint optimization problems. This paper presents a comprehensive survey of the applications, variants, and results of the so-called LSA. In LSA, the best-obtained solution is defined to improve the effectiveness of the fitness function through the optimization process by finding the minimum or maximum costs to solve a specific problem. Meta-heuristics have grown the focus of researches in the optimization domain, because of the foundation of decision-making and assessment in addressing various optimization problems. A review of LSA variants is displayed in this paper, such as the basic, binary, modification, hybridization, improved, and others. Moreover, the classes of the LSA's applications include the benchmark functions, machine learning applications, network applications, engineering applications, and others. Finally, the results of the LSA is compared with other optimization algorithms published in the literature. Presenting a survey and reviewing the LSA applications is the chief aim of this survey paper.
\end{abstract}

Keywords Lightning search algorithm (LSA) · Meta-heuristics · Optimization algorithms · Optimization problems

\section{Introduction}

Many real-world Engineering optimization problems present in different fields [1], such as engineering, science, finance, and decision-making, can not be solved using traditional mathematical techniques and methods within a reasonable time [2-5]. This is because real-world problem have many challenging such as uncertainties [6], parameter estimation [7], multi-objectives [8], constraints [9], and local search [10]. In order to deal with these difficulties, modern meta-heuristic algorithms (MAs), which are inspired by nature, are introduced and designed as stochastics techniques to find optimal or near-optimal solutions [11-14].

In Literature, meta-heuristics algorithms can be categorized as Evolutionary Algorithms (EAs), Human-based algorithms, Swarm Intelligence (SI) algorithms, and Chemistry and Physics algorithms [15]. The first class EAs contains algorithms which are based on the natural evolutionary

Laith Abualigah

Aligah.2020@gmail.com

Extended author information available on the last page of the article. process like crossover, mutation, selection, and recombination. Examples of EAs are genetic algorithm (GA) [16], differential evolution (DE) [17], genetic programming (GP) [18], and the bird mating optimizer (BMO) [19].

Human-based algorithms class contains an algorithm that simulates human beings' behavior. Examples of Humanbased algorithms are teaching-learning based optimization (TLBO) algorithm [20], socio evolution and learning optimization (SELO) algorithm [21], cognitive behavior optimization algorithm (COA) [22], the ideology algorithm [23], coronavirus herd immunity optimizer (CHIO) [24], human mental search (HMS) [25], and social learning optimization (SLO) [26].

The SI-based algorithms class contains algorithms which simulate the collective or social behavior of selforganization, decentralized and shape-formation, natural or artificial creatures [27]. The two most common classical examples of this class is particle swarm optimization (PSO) [28] which follows the flocking behavior of birds, ant colony optimization (ACO) [29, 30], which simulate the ant colony foraging. In literature, there are many recent proposed SI-based algorithms such as salp swarm algorithm (SSA) [31], grey wolf optimizer (GWO) [32], symbiotic organisms research (SOS) [33], whale optimization algorithm (WOA) [34], krill herd algorithm 
(KHA) [35], crow search algorithm (CSA) [36], salp swarm algorithm (SSA) [37], social spider optimization (SSO) [38], cuckoo search (CS) [39], firefly algorithm (FA) [40], antlion optimizer (ALO) [41], butterfly optimization algorithm (BOA) [42], multi-verse optimizer algorithm (MVO) [43], and Moth-flame Optimization (MFO) [44-46].

The last class Chemistry and Physics based algorithm are algorithms inspired from chemical reactions or physical laws/phenomena like Chemical reaction optimization (CRO) [47], multi-verse optimizer (MVO) [48], the mine blast algorithm (MBA) [49], water evaporation optimization (WEO) algorithm [50], ray optimization (RO) algorithm [51], Sonar inspired optimization (SIO) [66], simulated annealing (SA) [52], thermal exchange optimization (TEO) [53], Electromagnetic field optimization (EFO) [54], the big bang-big crunch (BB-BC) algorithm [55], atom search optimization (ASO) [56], Galactic swarm optimization (GSO) [57], and vortex search algorithm (VSA) [58].

Generally, meta-heuristic can be divided based on the number of solutions into two types: single-based solution and population-based. The former type as indicated by its name contains one solution during optimization process such as Tabu search (TS) [59, 60], SA, iterated local search (ILS) [61], VSA, guided local search (GLS) [62], and variable neighborhood search (VNS) [63]. The latter type population-based contains a set of individuals (solutions) that are evolved at each iteration-examples of this type PSO, GWO, WOA, SSA, and BOA. However, the singlebased algorithm has better exploitation capabilities, it can easily be trapped in local optima. On the other hand, population-based algorithms can improve search space by producing diverse solutions and enhancing exploration via various operators.

Lightning Search Algorithm (LSA) is a recently physicsbased population algorithm developed by Shareef et al. in [64], which is based on natural lightning phenomena. In LSA, three fast particles called projectiles are designed, which create the initial population of the leader, the projectiles which want to be a leader, and lead projectile.

Between new and notable meta-heuristics algorithms, LSA has gained significantly more attention from computer science and optimizations researchers. Also, LSA has been applied to an enormous number of domains and fields. Figure 1 shows the number of publications of the LSA algorithm since its appearance per publishers such as Elsevier, Springer, IEEE publisher. Also, Fig. 2, shows the LSA related papers distribution in different domains.

To best of our knowledge, no work in the literature has provided a detailed review of LSA. In this work, a comprehensive review of LSA is provided, all variants are compared and discussed, as well as its applications and results.

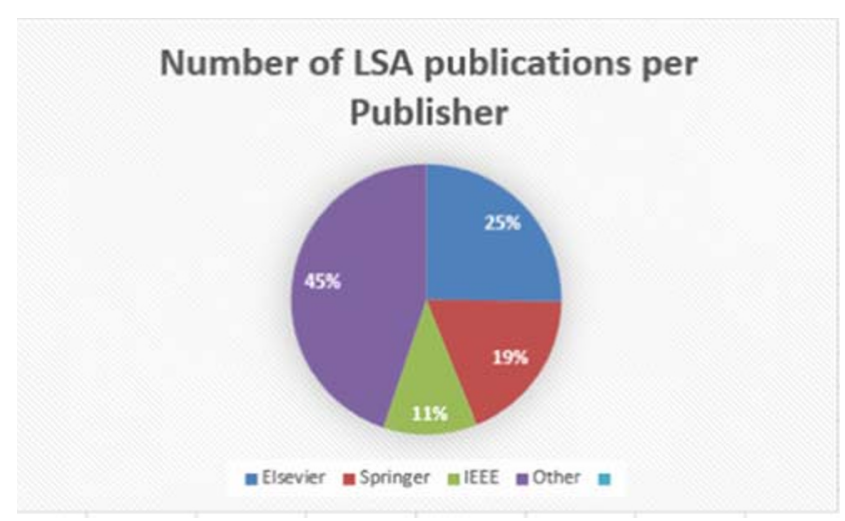

Fig. 1 Percentage of each publisher

The rest of this paper is organized as follows. Section 2 presents the procedures of the conventional Lightning Search Algorithm (LSA). Section 3 presents the variants of the Lightning Search Algorithm. Section 4 presents the application of the Lightning Search Algorithm. Section 5 presents the evaluation and analysis of the Lightning Search Algorithm. Finally, in Section 6, the conclusion and potential future work are presented.

\section{Lightning search algorithm (LSA)}

The lightning search algorithm (LSA) is a meta-heuristic technique that inspiration the natural phenomenon of lightning [64]. The LSA depends on the techniques of step leader (SL) propagation that assumed the projectiles are those the faster particles. To simulate the transition projectiles, three types of projectile are developed, and this formulated by creating the population of step leader, the space projectiles, and the lead projectile. In LSA, the space projectiles are those projectiles aimed to represent the leader in the next generation. In contrast, lead projectile refers to the projectile fired from the first type. Also, from the

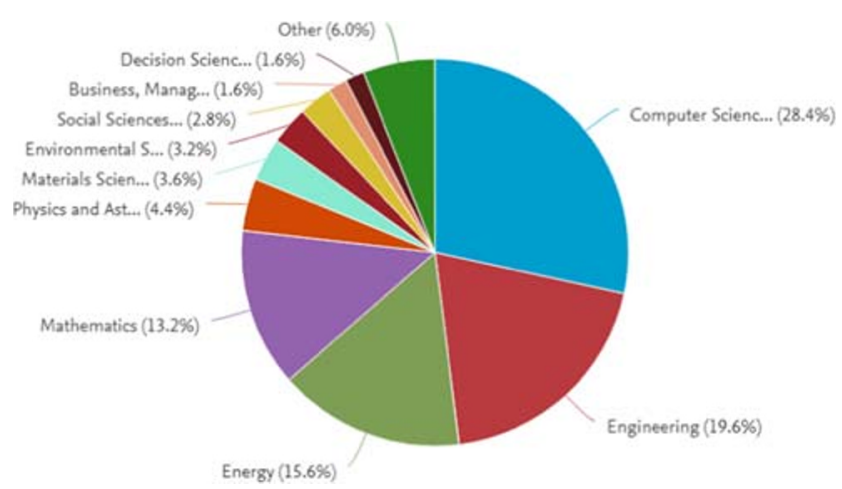

Fig. 2 Distribution of LSA related papers in different fields 
opposition theory, the concurrent formation of two leader tips at fork points and the exponential random behavior of a second type (i.e., space projectile) are used to simulate the exploration ability of LSA.

The first step in LSA is to determine the projectile that refers to the population. In contrast, the solutions of the population represent the tip of the current step leader. There are variants of stages of the LSA, and the details of each of them are given in the following.

\subsection{Properties of the projectile}

Followed [64], when the projectile travels under normal conditions through the atmosphere, its kinetic energy is decreased during the collisions with atoms and molecules in the air. The velocity of a projectile is formulated as:

$v_{p}=\left[1-\left(1 / \sqrt{1-\left(v_{0} / c\right)^{2}}-s \times F_{i} / m \times c^{2}\right)^{-2}\right]^{-1 / 2}$

Where $v_{p}$ and $v_{0}$ represent the initial velocity and current velocity of the projectile, respectively, $c$ and $F_{i}$ are the speed of light and rate of ionization (it is constant). While $m$ represents the mass of the projectile, and $s$ indicates the length of the path. From (1) it is observed that the velocity depends on the mass of the projectile and the position of leader tip. So, the exploration and exploitation of LSA can be managed by using the relative energies of the SLS.

The SL has another property called forking that occurred when two symmetrical and simultaneous branches have emerged. Due to the nuclei collision, this phenomenon is rarely performed. The forking can be simulated using two strategies, 1) using the opposite number to represent the creation of symmetrical channels during the nuclei collision as in the following equation:

$\bar{p}_{i}=U B+L B-p_{i}$

where $p_{i}$ and $\bar{p}_{i}$ represents the projectiles and its opposite, respectively. While, $U B$ and $L B$ are the limits of search space.

Meanwhile, 2) for forking a channel is considered to displayed at SL tip due to the unsuccessful leader are redistributed after several trials of the propagation. This performed by representing the channel time using the maximum allowable number of trials and the size of the population not increased in this case.

\subsection{Projectile modeling and movement of SL}

A set of three types of the projectile are applied to form the transition projectiles (TP), which used to construct the first-step leader (FSL) population $N$. Also, they are used to create the space projectiles (SP) that try to find the position of the best leader. Likewise, those types are used to build the lead projectiles (LP) that refer to the best position overall $N$ (SL). For clarity, the details of each type are given in the following.

\subsubsection{Transition projectile}

Followed [64], the leader tip is constructed at an early phase due to the ejected projectile is randomly created from thunder cell using the transition. Thus, it can be represented by generating a random number from a uniform distribution that defined in (3).

$f\left(x^{T}\right)= \begin{cases}1 / b-a & \text { for } a \leq x^{T} \leq b \\ 0 & x<a \text { or } x>b\end{cases}$

where $a$ and $b$ refer to the limited of the search space. $x^{T}$ refer to a solution or tip energy $\left(E_{s l, i}\right)$ of SL $\left(s l_{i}\right)$. For the population which has $N$ SL (i.e. $S L=\left[s l_{1}, s l_{2}, \ldots, s l_{N}\right]$ ), a set of $N$ projectiles $P T=\left[p_{1}^{T}, p_{2}^{T}, \ldots, p_{N}^{T}\right]$ are needed.

\subsubsection{Space projectile}

In LSA, the Space projectile (SP) is represented as a random number produced using the exponential distribution that defined as:

$f\left(x^{S}\right)= \begin{cases}\frac{1}{\mu} e^{-x^{S} / \mu} & x^{S} \geq 0 \\ 0 & \text { otherwise }\end{cases}$

where $\mu$ is the shape of the distribution and it is used to control on the space projectile $P^{S}=\left[p_{1}^{S}, p_{2}^{S}, \ldots, p_{N}^{S}\right]$ at step +1 . The $\mu$ for the $i$ th SP is defined as the distance between it (i.e., $p_{i}^{S}$ ) and the leader project $p^{L}$. Based on this definition, the value of $p_{i}^{S}$ is updated using the following formula:

$p_{i_{n} e w}^{S}=p_{i}^{S} \pm \operatorname{exprand}\left(\mu_{i}\right)$

where exprand represents an exponential random number with shape $\mu_{i}$. In the case of the value of $p_{i}^{S}<0$, then exprand should be subtracted since (5) provides values greater than zero. However, $p_{i_{n} \text { ew }}^{S}$ guarantee stepped leader propagation when the projectile energy $E_{p_{i}}^{S}>E_{s l_{i}}$ until a good solution is obtained. The $p_{i}^{S}$ and $s l_{i}$ can be extended to a new position $p_{i_{n} e w}^{S}$ and $s l_{i_{n} e w}$, respectively, when its corresponding $p_{i_{n} e w}^{S}$ at step +1 obtains good solution. Otherwise, both of them (i.e., $p_{i}^{S}$ and $s l_{i}$ ) not unchanged until the step. 


\subsubsection{Lead projectile}

Similar to SP, the Lead projectile (LP) can be updated expected it formulated using a random number which generated from a normal distribution that deified as:

$f\left(x^{L}\right)=\frac{1}{\sigma \sqrt{n \pi}} e^{-\left(x^{L}-\mu\right)^{2} / 2 \sigma^{2}}$

where $\sigma$ and $\mu$ represent the scale and shape of the distribution, respectively. The position of $\operatorname{LP}\left(p^{L}\right)$ is updated using normal random number normrand as defined in (7).

$p_{i_{n} e w}^{L}=p_{i}^{\lfloor} \pm \operatorname{normrand}\left(\mu_{L}, \sigma_{L}\right)$

The steps of the LSA is summarized in flowchart Fig. 3.

\section{Variants of lightning search algorithm}

In this section, the variants of the Lightning Search Algorithm are presented.

\subsection{Basic of lightning search algorithm}

LSA is an abbreviation of the Lightning Search Algorithm, which is a recent population-based meta-heuristic algorithm developed by Shareef et al. [64]. LSA is based on a lightning step leader propagation structure. It regards the fast projectiles (particles) involvement in the binary tree structure formation of step leader. LSA algorithm mainly consists of 3 steps: projectile and propagation of the step leader, properties of the projectile, and projectile modeling
Fig. 3 Flowchart of the Lightning search algorithm (LSA) [64]

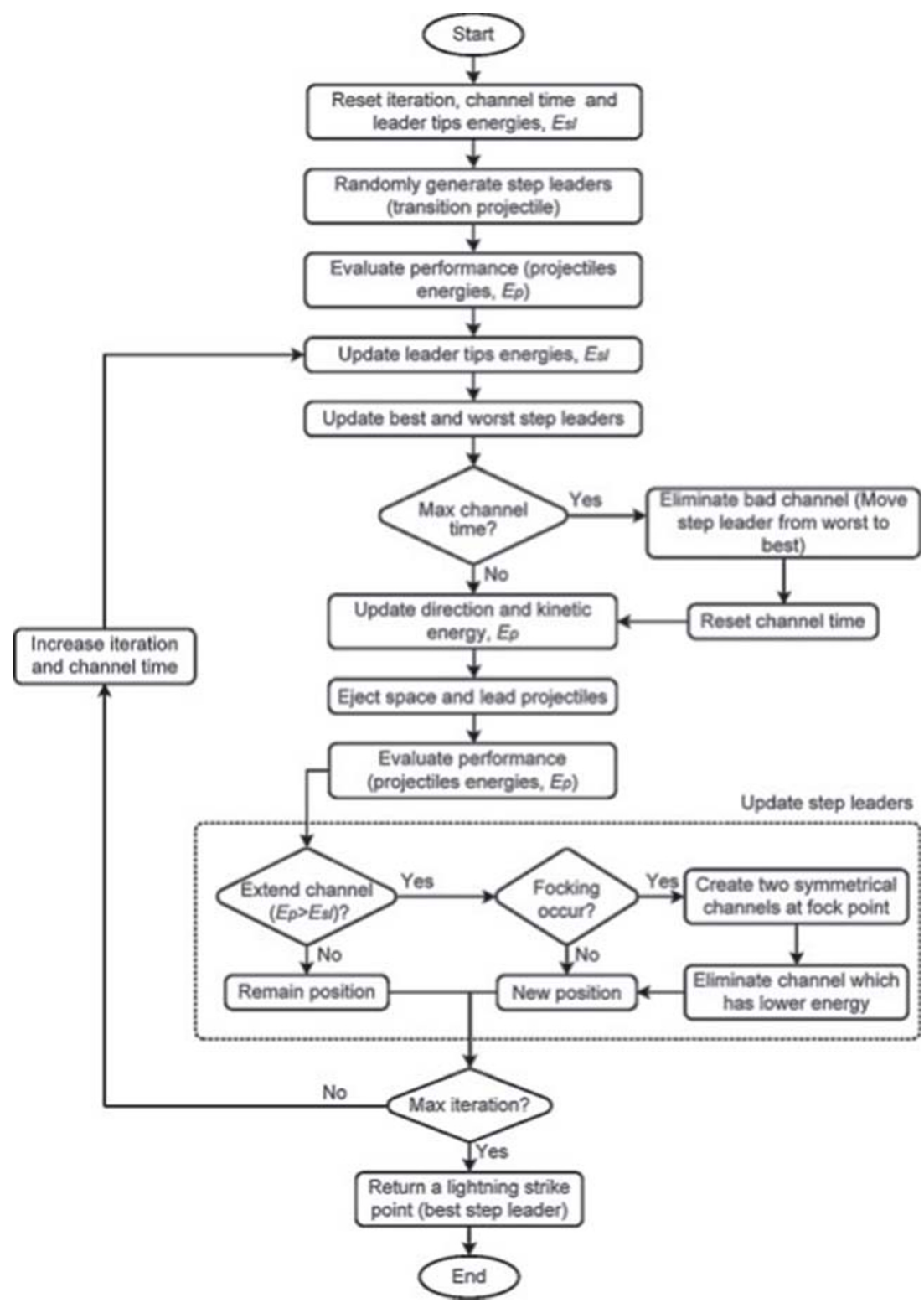


and movement. A projectile loses its kinetic energy when traveling under reasonable conditions.

This paper aims to propose an algorithm (LSA) to solve the problems of restrictions [64]. This depends on the phenomenon of lightning in nature and uses the concept of rapid particles called bombers, through which three types of planes were developed and produced. In the first stage, the leader of the population. The second stage, produced space projectiles that want to become a pilot, and the third is a lead shell that depends on the best missile from the commander. The exploration feature was designed using exponential and random fencing of the projectile, which coincides with the leader's advice at common points and relies on opposition theory. Where the proposed algorithm was evaluated by doing a test of (LSA) based on a set that has 24 functions of different characteristics. This study utilizes four different known methods, where the results were better than other methods.

\subsection{Binary of lightning search algorithm}

The proposed algorithm in this paper [65] deals with binary optimization problems using several optimization algorithms. The proposed algorithm added some modifications to the basic LSA to make it binary algorithm, called binary lightning search algorithm (BLSA). BLSA is tested on special benchmark functions and compared to other binary optimization methods to confirm its efficiency. Experiment results exposed that the projected binary algorithm achieved better results in terms of search accuracy and convergence than within the multidimensional search space. The results illustrated that the proposed algorithm archived better results in comparison with other optimization methods.

A new optimization method, based on binary LSA, is proposed in [66] to solve environmental problems, called BLSA. These problems are released due to global warming, and some concerns such as battery charging, economical energy drainage from the battery, and identification of the best paths and speed pathways to reduce power. The performance of the proposed BLSA algorithm is evaluated using the IEEE 34-bus benchmark. The optimization process aims to get the lowest daily exchange and minimize energy loss by $10 \%$. The results illustrated that the proposed algorithm archived better results in comparison with other traditional optimization methods.

\subsection{Modifications of lightning search algorithm}

This paper proposes a quantum lightning-based algorithm (QLSA) based on controlling the speed of disk drives called search engines (IM) to develop the algorithm (QLSA) [67]. Through which the speed of the chat engines was managed to create an input and output function to suit the speed of the motor.

To develop a device that controls the speed of the algorithm (QLSAF) through the algorithm (QLSA), aims to reduce the average error in the rate of search engines, and deal with variables in speed and mechanical load. During the application of this algorithm in a simulation model in Mat lab, for testing and controlling the search process in search engines. The results were that it was agreed with the control parameters with simulation results in many different circumstances, and was an indicator of the algorithm (SPVWM) as well as the speed and stator responded with the simulation results, as well as checking the Health Controller (QLSAF) provided [67]. It outperformed other studies in time results in simulation.

This paper proposed a new method to obtain the optimum result for power supply, by using an improved quantum lightning-inspired search algorithm (QLSA) [68]. The proposed method is used in Pharmaceutical Quality Management Systems to monitor optimum energy quality and its location in the power scheme to control power and voltages. This method is applied and tested in the IEEE 118-bus. The results showed that the proposed QLSA reported excellent performance in comparison with other optimization methods.

This paper developed a new method to upgrade the fieldoriented indirect fog control technology for management in three-phase induction motors (TIM). The proposed method is based on the quantum-inspired lightning search algorithm, called QLSA [69]. The induction phases are Induction Engine (IM) layout decreases fitness function, adaptive PI controls produced, and fuzzy organic functions (MFs). The obtained results of the proposed algorithm properly overcome the other optimization algorithms in all exams of the corresponding reaction. The results illustrated that the proposed algorithm archived better results in comparison with other optimization methods. Moreover, it is an efficient method for advanced control problems.

Lack of confidence in the amount of energy generated by wind turbines and advanced transportation aspects such as effort remains interactive energy management despite the availability of energy for networks in the form of many wind farms in parts of the world. Therefore, it became something that required further consideration and updates. A discrete LSA is proposed for solving the wind frames [70]. The use of inductive generators, additional transformers and capacitors is a problem for system harmonics, so interest in wind farms is required. Also, the location and size of capacitors on wind farm buses are $80 \mathrm{MW}$ for wind speed style, system equivalent circuits, and harmonics to reduce losses. The separate release of the DLSA lightning algorithm is a robust and flexible technology. The results 
illustrated that the proposed algorithm archived better results in comparison with other optimization methods.

\subsection{Hybridizations of lightning search algorithm}

One of the factors that affect enhancing the quality of the electrical structures is electrical harmonics. This paper suggested a creative design of a harmonic estimator using a pilot optimization technique enthused by the lightning search algorithm (LSA) to generate correct approximations for the estimator, which is vital and needed [71]. The suggested design is tested on many levels of noise and time-varying signals. Also, there was a comparison with the previous methods used, such as a modified artificial bee colony (MABC), which confirmed the efficiency of the proposed estimator suggested design method. The results illustrated that the proposed algorithm archived better results in comparison with other optimization methods.

Three projectile types are developed to represent the transition projectiles that create the first step leader population. These space projectiles attempt to become the leader and the lead projectile that represents the projectile fired from the best-positioned step leader. In contrast to that of the counterparts of the (LSA), the proposed algorithm is modeled using the exponential random behavior of space projectile and the concurrent formation of two leader tips at fork points using opposition theory to evaluate the reliability [64]. The efficiency of the proposed algorithm (LSA) is tested using a well-utilized set of 24 benchmark functions with various characteristics necessary to evaluate a new algorithm. An extensive comparative study with four other well-known methods is conducted to validate and compare the performance of the (LSA). Generally. The proposed algorithm provided better results compare with the other tested methods with a high convergence rate.

\subsection{Multi-objective of lightning search algorithm}

The problem of the distributed systems lies in their loss of energy in addition to the stability of the effort, and this gives the studies and researches interest [72]. Therefore, it became necessary to pay attention to research and improve operating conditions. Various studies and research have discussed how to reduce energy losses and how to enhance voltage stability. In this paper, a new methodology is proposed to achieve optimal allocation using the Lightning Search Algorithm (LSA) [73]. The research includes a unique multi-objective function that reduces energy losses and maximizes the voltage stability indicator, where different loads are used from light to maximum load with a step size. The optimum amount of storage in each download level is calculated. The proposed method is tested on the IEEE 33 and 69 system. The results confirmed that the main goal is achieved as the stability of the effort is enhanced; the energy losses are reduced by using the LSA. This work is adopted in the long run in planning distribution networks. The results illustrated that the proposed algorithm archived better results in comparison with other optimization methods.

Network-to-grid transmission technology (V2G) has become an essential mechanism for providing the power source to distribution networks for what they play in the role of electric hybrid electric vehicles (PHEV) during charging mode [74]. Because vehicles need charging stations (CS) to receive energy, an optimum position (CS) is specified in the distribution network in order to enhance the performance of this network at the time of ordering. Here a general discussion is taken to evaluate the optimal situation when installing (CS) in the distribution network. In this paper, the LSA is proposed in a binary format to improve the detection of events, after which a multi-objective function is set to take advantage of $(\mathrm{V} 2 \mathrm{G})$ technology. This is to reduce line load, voltage deviation, and circuit power loss. As a result of comparing the method with the performance of other indicative improvement techniques, a proposed algorithm has fewer limitations in terms of previous convergence than other heuristic improvement techniques.

In the problem of power flow, there is a realistic optimal power flow is an anon-convex and complicated problem which tries to economically dispatch the load between different generation units and some other objective functions, while- commensurable and contradictory objectives namely total fuel cost, total emission, and total real power loss are considered which conclude to a multi-objective (MO). This paper proposes multi-objective electromagnetism -like algorithm (MOEMA) based on the Pareto dominance concept and external archive strategy to solve the formulated (MO) problem [75]. The feasibility and effectiveness of the proposed method are tested on the IEEE-30bus test system, and obtained numerical results of the other heuristic methods reported in literature. The single and (MO) optimization results prove the effectiveness of the proposed optimization algorithms over other methods.

Advanced long-term scheduling of DG and DSTAT is proposed for the radial distribution networks based on using LSA [73]. It has several objectives, including reducing energy loss and total voltage deviation (TVD) and maximizing equal voltage stabilization index (VSL) and restrictions of inequality. An optimization algorithm solved this multi-objective problem called a lightningsearch algorithm (LSA). The diversity of the feed unit loads is linear from the light load (0.5) to a higher load (6.1) with a step size of $1 \%$. In each step, the optimum scaling is calculated; calculated for ( DG ) and (DSTATCOM) via (LSA) using Curve Composition Technology (CFT). At each stage, the volume of (DG) and (DSTATCOM) is changed in the form of a generalized formula. This equation 
helps distribution network operators (DNOs) determine the sizes of (DG) and (DSTATCOM) due to load changes. The proposed method has been tested on bus and bus pronouncements in different cases. The results illustrated that the proposed algorithm archived better results in comparison with other optimization methods.

\section{Application of lightning search algorithm}

In this section, the applications of the Lightning Search Algorithm are presented.

\subsection{Test function applications}

In [76], an improved quantum lightning search algorithm (LSA) was proposed, which called (QLSA). The theory of quantum strategy is to improve each search step leader to get the best position. Eighteen test functions with different features were used to assess the efficiency and reliability of the proposed algorithm. The design of the disturbed logical console (FLC) was optimized to control the engine's response speed. The results illustrated that the proposed algorithm archived better performance in comparison with other optimization methods.

In another work, a new version of the lightning search algorithm, which is called (BLSA) has been proposed [77]. In BLSA, the standard functions of the transport in the LSA algorithm have been relied upon, which is the logistic year by examining the segmental segued. The quantum rotary gate that is used in the original algorithm (LSA). These functions are evaluated by using standard tools, and then the features and results were compared with other improvement techniques. This study revealed that the function of overload had boosted the performance of the BLAS algorithm. The results illustrated that the proposed algorithm archived better performance in comparison with other optimization methods.

\subsection{Machine learning applications}

Machine learning domain is a promising search area [78]. In another work, the LSA algorithm has been used for classification [79]. Initially, problems were identified for the first time and the convergence speed of sophisticated and progressive algorithms [79]. Through the LSA algorithm, a trainer was adopted with a set of performance studies. Moreover, represented by measurement data such as (appendicitis, liver, breast cancer, primary diagnosis, second diagnosis, Parkinson's disease, and diabetes) and then used a set of quantitative and qualitative measurement tools for comparison. To achieve the goal, research training algorithms (GA, DE, ES) and swarm-based algorithms
(PSO, ACO, ABC) and gradient algorithms (LM, BP) were used. The results showed that this algorithm works more powerfully than the rest of the algorithms in analyzing the results by determining the cause of the problem and by relying on the calculation and analysis of the standard deviation of the results.

\subsection{Engineering applications}

Syed Nasir et al. [80] presented mitigation of harmonic distortion caused by indicting station at the selected bus rates. The authors in this paper are concluding that the proposed algorithm, modified LSA, got appropriate positions and best dimensions of multiple variable passive filters (VPF). The proposed modified LSA is introduced to find twenty-two units of VPF coordination considering the varying of patterns, harmonic impact, reducing power loss, less harmonious based on $415 \mathrm{~V}$ bus to the medium-voltage network. Power system harmonious flow, VPF, CS, battery models have been built and analyzed by MATLAB $/ \mathrm{m}$ file platform. The results illustrated that the proposed algorithm archived better results in comparison with other optimization methods.

Identifying the photovoltaic models is a common engineering problem [81]. A new approach to generate a proper and correct illustration of solar cells (SCs) features is proposed based on voltage $(\mathrm{V})$ and current $(I)$ relation [82]. The proposed approach is based on using the improved version of the lightning search algorithm (LSA) to obtain the parameters of one single diode and paired diode (SCs) as well as for a photovoltaic (PV) unit. Several factors were considered, such as the influence of varying shading environments and different temperatures. At the same time, most of the previous tests were only derived for one cell type, or (PV) unit. Experiments are conducted on multicrystalline KC200GT and monocrystalline SQ150-PC solar panels for testing purposes. Data in these experiments were gathered at a similar temperature in five diverse radiation levels to get accurate results. The results illustrated that the proposed algorithm archived better results in comparison with other optimization methods in terms of I and V, accuracy, and speed. Furthermore, the value of the objective function using LSA was lower.

After the development in the modern world and with what is called the dynamic world, the concentration of air pollution affects the generation of energy, which led to its change from traditional methods to non-traditional methods. The factors affecting the real power loss of the system are the optimal size and location of the DG and the fixed distribution date, and also change the improvement of the voltage of the distribution system. In this paper, the lightning search algorithm (LSA) is proposed to find the optimal position in the distribution system [83]. The main 
goal of the proposed algorithm is to reduce real energy losses in the distribution system. The IEEE-33 transcriber standard test system is used to examine the proposed method; the final results indicated that the performance of the proposed algorithm is better than other comparative optimization methods.

Although wind farms are prevalent in most countries of the world, and their adoption by providing energy in an obvious way, they are still vague regarding the amount of electricity generated by wind turbines, as well as concerning operational aspects, effort, and interactive energy management, and this requires further development. A somewhat simple and inexpensive method has been suggested, which is to optimize the capacitor in wind farms to solve the problem of the vulnerability to compensate for the reactive capacity of wind farms. However, the potential problems with system harmonics represented by the use of induction generators and additional capacitors as well as inverters, so they must be considered. A new version of the lightning search algorithm is proposed as a robust optimization technique to solve wind farms [70]. The results illustrated that the proposed algorithm archived better results in comparison with other optimization methods.

The problem of optimal energy flow and the facts of the flexible current transfer system was able to solve by the increase in planning and operated the modem power systems. The thyristor-controlled series capacitor was used and suggested as a solution for this problem using a new indicative algorithm it was known as the Lightning Search Algorithm based on the phenomenon of Lightning [84]. Moreover, testing in the Institute of Electrical and Electronics Engineers test systems, which are the modified IEEE-30bus and IEEE-7bus test system. The LSA method is generated from the mechanism of step leader performance, and the success of this problem is evaluated and tested on IEEE-30bus and IEEE-7bus test system. The results illustrated that the proposed algorithm archived better results in comparison with other optimization methods.

Electrical energy depends on power plants that use the fuel for power generation. Therefore, the distance between the power plant and consumers is remote, and this requires energy-transportation [85]. These cause energy loss due to the length and aging of traffic, and the gas emissions that contribute negatively to the climate, and other adverse effects on security and environment. The LSA algorithm is proposed to solve the power generation problems [86]. The increasing population and pressure on the electricity networks constitute an enormous pressure on the companies providing this service, as the expansion of electricity generation requires the development of both transportation and distribution. As power grids evolve from fixed infrastructure to scalable networks called smart grids, smart grids and small grids (MGs) include new communication channels, digital and intelligent control to provide rapid response required, and meet ongoing demand and urgency. Renewable energy systems can be used to treat energy loss during transportation, reduce operating costs, and reduce environmental pollution. The results illustrated that the proposed algorithm archived better results in comparison with other optimization methods.

Wave receivers are used to reduce radar echoes from non-flying rooms and aircraft, and to achieve military concealment technology. The electronic devices are protected by absorbing materials to reduce the radar cross-section of various objects. Because of the low electromagnetic parameters of the modification, the single-layer absorption has the disadvantages of narrow frequency range and compact structure. In the last period, some researchers focused on multilayer absorption. Multilayer microwave absorption properties are related to accident frequency, angle, electromagnetic parameters (permittivity and permeability) of materials, thickness, and arrangement of each layer. In this paper [87], a new optimization method is proposed based on using a hybrid binary, called LSA BLSA-SA. The proposed method works to optimize the absorption of a multilayer microwave Transformation Circumflex, which can improve the absorption parameters to resolve the bilateral problem. The results illustrated that the proposed algorithm archived better results in comparison with other optimization methods.

FACTS devices are static power-electronic devices installed in $\mathrm{AC}$ transmission networks to increase power transfer capability, stability, and controllability of the networks through series shunt compensation [88]. These devices are also employed for congestion management and loss optimization. The static synchronous series compensator (SSSC) and thyristor-controlled series capacitor (TCSC) are control devices. Which provide series compensation to the reactance of the lines to which they are connected. In contrast, the static synchronous compensator (STATCOM) and static VAR compensator (SVC) (where VAR stands for volt-ampere reactive) are FACTS devices that provide shunt compensation to transmission lines. FACTS control devices also provide adequate damping of interarea oscillations by acting as actuators in robust control schemes and PMU-based wide-area control schemes.

After experiencing wind energy as a source of renewable energy that is less expensive and polluting the environment, the ability to correctly predict the energy produced from wind stations has become an essential matter for operating and organizing energy distribution. The proposed LSA is proposed to determine the wind energy in this paper [89]. Forecasting helps determine the size of the electricity reserve and managing the network's work: physical and Statistical AI and hybrid methods. The results illustrated that the proposed algorithm archived better results in comparison with other optimization methods. 
The world and its recent developments focus on pollution in the atmosphere, which is changing the power of a generation from the traditional to the unconventional. Generations are distributed respectively to be assimilated with the distribution systems, the optimum size and location of the distributed generation (DG), and the fixed compensated distribution (DSTATCOM) that affect the real energy loss system, and the magnitude of the voltage in the distribution system. The LSA search algorithm is used in [83] to find out the optimal situation in (DG) and (DSTATCOM) in the distribution system. The main objective is to reduce the real energy losses in the distribution system. The results illustrated that the proposed algorithm (LSA) archived better results in comparison with other optimization methods.

To overcome the time-consuming, trial-and-error mechanism that is used to optimize the piezoelectric energy harvesting system (PEHS) converter, the LSA algorithm has been used in [90]. LSA algorithm was utilized to tune the optimal parameter values of the PI controller for the PEHS converter. The LSA algorithm has been compared with other meta-heuristics, and the experimental results proved that LSA has found a minimum error of objective function mean absolute error (MAE) and much faster than the other method.

Due to the complexity of the distribution system, especially after the rapid development of EV and the presence of distributed generation, a modified version of the LSA algorithm (MLSA) has been used in [91] to find the optimal solution. Mainly, MLSA has been used to identify optimized locations and sizes for three sets of filters in the 33-bus radial distribution system. In their work, some modifications of the classical LSA have been made to improve its performance. As the original channel time is not suitable when dealing with the problem that has many local minima, the first enhancement was to channel time. A new updating approach has been used to check the forward or backward direction. From the experimental results, it has been proven that MLSA with the Pareto-Fuzzy method is capable of providing the best location and size of filters.

Elsisi and Abdelfattah [92] used the lightning search algorithm (LSA) to optimize the parameters of the variable structure controller (VSC) for a nuclear reactor power system to replace the traditional trial and error or the designer's expertise methods. In particular, the LSA algorithm has been used to efficiently tune the feedback gains, and the sliding equation gains of the VSC to achieve better performance. In their work, a comparison between the genetic algorithm and the LSA algorithm has been performed, and the results proved the superiority of the suggested VSC based on the ICA algorithm. The authors concluded that the use of the proposed VSC controller based on the LSA algorithm to the nuclear reactor control problem significantly improved the system performance.

In another work, a quantum lightning search algorithm (QLSA) has been used to propose an improved proportional-integral-derivative (PID) controller design technique for controlling a three-phase induction motor (TIM) speed drive [93]. This proposed controller avoids the exhaustive conventional trial and error procedure for obtaining PID parameters. The Objective function utilized in the proposed controller was the mean absolute error (MAE) to enhance the TIM speed performance under sudden change of the speed and load conditions. The QLSA is used to improve two controller system PID and PI controllers in the TIM drive. Moreover, the QLSA algorithm was compared with three optimization algorithms, namely, the lightning search algorithm (LSA), the backtracking search algorithm (BSA), the particle swarm optimization (PSO). The results revealed that the proposed algorithm outperformed the other compared algorithms.

\subsection{Network applications}

Several network applications used optimization problems to improve their efficacy, including cloud computing [94], wireless sensor networks [95], intrusion detection [96], etc.

A new optimization method was proposed based on using Lightning Search Algorithm to determine the optimal employment of the charging station (CS) in the distribution network to use V2G technology [74]. The proposed method was used to improve the performance of the network used in hybrid electric vehicles, as these vehicles need charging stations (CSs) to receive energy, and they also need a backup power source. The technology of transmission from the network to the network (V2G) is the technology currently used in those vehicles that are powered by electricity during the discharging mode, as this technology has become an important mechanism to provide a backup power source for distribution networks. The optimal use of CS stabilization is presented using the proposed binary quantum lightning search algorithm. There is a multipurpose function to use V2G technology that reduces line loading, voltage deviation, and circuit power loss, and the proposed method is compared to other optimization techniques. The results illustrated that the proposed algorithm archived better results in comparison with other optimization methods. Moreover, the proposed algorithm got a small number of determinants of the convergence of temperatures compared to other techniques.

Liu et al. [97] studied environmental factors and some difficulties that affect the accuracy of wireless sensor networks (WSN) localization of the miscalculation when the node is located. These difficulties are the differences 
between the measured and actual yields distance. The proposed method enhanced the efficiency of the basic lightning search algorithm (LSA) by applying a new technique to WSN localization [97]. The comparisons were conducted with other optimization algorithms to the general location. The obtained results of the proposed method confirmed that (LSA) generated enhanced outcomes in the merging and position precision of WSN. The results illustrated that the proposed algorithm archived better results in comparison with other optimization methods.

Asvany et al. [98] represented a solution based on using LSA to the problem of coverage in wireless sensor networks and is closely related to the quality of service. The coverage problem makes sure that each node is in the target field within the transmission band that makes up the network. Experimental results in many studies have shown that there are very fruitful solutions to the coverage problem in the wireless sensor network. In this paper, the authors seek to clarify and find a solution to the problem of coverage in wireless sensor networks, which reflected the quality of service. Some research has described reasonable solutions to address the coverage issue in the wireless sensor network. Most research in the field of wireless communications is in the area of the wireless sensor network. The wireless sensor network is used to collect the most significant amount of data in a dynamic, volatile environment.

To ensure the security of the network, [99] proposed a new version of the LSA algorithm, which is called a lightning search algorithm optimized extreme learning machine (LSA-ELM). LSA-ELM was utilized to optimize the parameters in the process of network intrusion detection by an extreme learning machine. In the first step, the parameters of extreme learning machines were coded as the discharge projectile position, and the total weighted error was taken as the fitness value. Then the optimal parameters of the extreme learning machine were found by simulating the lightning discharge behavior, and a network intrusion detection classifier was established. The experimental results proved that LSA-ELM improved the accuracy of network intrusion detection and fulfilled the requirements of online intrusion detection.

\section{Evaluation and analysis of the LSA algorithm}

\subsection{Benchmark functions}

In this section, we provide a depth set of benchmark evaluation problems (as seen in Tables 2-3) to test, analyze and demonstrate the efficacy of the LSA algorithm in comparison to other relative optimization algorithms including Whale Optimization Algorithm (WOA) [100],
Table 1 Parameters values of the LSA method and other comparative methods

\begin{tabular}{lll}
\hline Algorithm & Parameter & Value \\
\hline WOA & $\alpha$ & Decreased from 2 to 0 \\
& $b$ & 2 \\
SSA & $v_{0}$ & 0 \\
DA & $w$ & $0.2-0.9$ \\
& $s, a$, and $c$ & 0.1 \\
& $f$ and $e$ & 1 \\
ALO & $I$ ratio & $10^{w}$ \\
& $w$ & $2-6$ \\
LSA & Channel time & 10 \\
\hline
\end{tabular}

Salp Swarm Algorithm (SSA) [101], Dragonfly Algorithm (DA) [102], and Ant Lion Optimizer (ALO) [103].

All experiments are conducted 30 times (runs), and the maximum number of iteration is fixed to 1000 for all tested algorithms to make fair comparisons. The parameters setting are taken from the original papers, as mentioned before. The algorithms codes are taken from the Mathworks site as follows.

$$
\begin{aligned}
& \text { 1- } \mathrm{WOA}^{1} \\
& \text { 2- } \mathrm{SSA}^{2} \\
& \text { 3- } \mathrm{DA}^{3} \\
& \text { 4- } \mathrm{ALO}^{4} \\
& \text { 5- } \mathrm{LSA}^{5}
\end{aligned}
$$

The setting parameters values for the comparative methods are presented in Table 1. Figure 4 show the details of the used 23 benchmark function that generally used to test any optimization algorithm [104-108]. Table 2 show the results of the comparative methods on 13 benchmark functions (F1-F13) and Table 3 show the results of the comparative methods on 10 benchmark functions (F14 F23).

As Tables 2-3 reveal, the acquired results indicate that the LSA in these experiments obtained better and promising results in nearly all test functions. First of all, the LSA provides more (better) consistent performance on four of seven unimodal benchmarks. The results confirmed that LSA had a high search potential to solve the problems and stable convergence rates due to the characteristic features of

\footnotetext{
${ }^{1}$ https://www.mathworks.com/matlabcentral/fileexchange/ 55667-the-whale-optimization-algorithm

${ }^{2}$ https://www.mathworks.com/matlabcentral/fileexchange/ 63745-ssa-salp-swarm-algorithm

${ }^{3}$ https://www.mathworks.com/matlabcentral/fileexchange/ 51031-dragonfly-algorithm-toolbox

${ }^{4}$ https://www.mathworks.com/matlabcentral/fileexchange/ 49920-ant-lion-optimizer-alo

${ }^{5}$ https://www.mathworks.com/matlabcentral/fileexchange/ 54181-lightning-search-algorithm-1sa
} 


\begin{tabular}{|c|c|c|c|c|}
\hline Function & Description & Dimensions & Range & $f_{\min }$ \\
\hline F1 & $f(x)=\sum_{i=1}^{n} x_{i}^{2}$ & $10,50,100,500$ & {$[-100,100]$} & 0 \\
\hline F2 & $f(x)=\sum_{i=0}^{n}\left|x_{i}\right|+\prod_{i=0}^{n}\left|x_{i}\right|$ & $10,50,100,500$ & {$[-10,10]$} & 0 \\
\hline F3 & $f(x)=\sum_{i=1}^{d}\left(\sum_{j=1}^{i} x_{j}\right)^{2}$ & $10,50,100,500$ & {$[-100,100]$} & 0 \\
\hline $\mathrm{F} 4$ & $f(x)=\max _{i}\left\{\left|x_{i}\right|, 1 \leq i \leq n\right\}$ & $10,50,100,500$ & {$[-100,100]$} & 0 \\
\hline F5 & $f(x)=\sum_{i=1}^{n-1}\left[100\left(x_{i}^{2}-x_{i+1}\right)^{2}+\left(1-x_{i}\right)^{2}\right]$ & $10,50,100,500$ & {$[-30,30]$} & 0 \\
\hline F6 & $f(x)=\sum_{i=1}^{h}\left(\left(x_{i}+0.5\right]\right)^{2}$ & $10,50,100,500$ & {$[-100,100]$} & 0 \\
\hline F7 & $f(x)=\sum_{i=0}^{n} i x_{i}^{4}+\operatorname{random}[0,1)$ & $10,50,100,500$ & {$[-128,128]$} & 0 \\
\hline F8 & $f(x)=\sum_{i=1}^{n}\left(-x_{i} \sin \left(\sqrt{\left|x_{i}\right|}\right)\right)$ & $10,50,100,500$ & {$[-500,500]$} & $-418.9829 \times n$ \\
\hline F9 & $f(x)=\sum_{i=1}^{h}\left[x_{i}^{2}-10 \cos \left(2 \pi x_{i}\right)+10\right]$ & $10,50,100,500$ & {$[-5.12,5.12]$} & 0 \\
\hline F10 & $f(x)=-20 \exp \left(-0.2 \sqrt{\frac{1}{n} \sum_{i=1}^{n} x_{i}^{2}}\right)-\exp \left(\frac{1}{n} \sum_{i=1}^{n} \cos \left(2 \pi x_{i}\right)\right)+20+e$ & $10,50,100,500$ & {$[-32,32]$} & 0 \\
\hline F11 & $f(x)=1+\frac{1}{4000} \sum_{i=1}^{n} x_{i}^{2}-\prod_{i=1}^{n} \cos \left(\frac{x}{\sqrt{i}}\right)$ & $10,50,100,500$ & {$[-600,600]$} & 0 \\
\hline \multirow[t]{2}{*}{ F12 } & 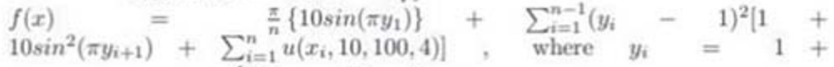 & $10,50,100,500$ & {$[-50,50]$} & 0 \\
\hline & $\frac{x_{i}+1}{4}, u\left(x_{i}, a, k, m\right) \begin{cases}K\left(x_{i}-a\right)^{m} & \text { if } x_{i}>a \\
0 & -a \leq x_{i} \geq a \\
K\left(-x_{i}-a\right)^{m} & -a \leq x_{i}\end{cases}$ & & & \\
\hline F13 & $\begin{array}{l}f(x)=0.1\left(\sin ^{2}\left(3 \pi x_{1}\right)+\sum_{i=1}^{n}\left(x_{i}-1\right)^{2}\left[1+\sin ^{2}\left(3 \pi x_{i}+1\right)\right]+\left(x_{n}-1\right)^{2} 1+\right. \\
\left.\sin ^{2}\left(2 \pi x_{n}\right)\right)+\sum_{i=1}^{n} u\left(x_{i}, 5,100,4\right)\end{array}$ & $10,50,100,500$ & {$[-50,50]$} & 0 \\
\hline F14 & $f(x)=\left(\frac{1}{300}+\sum_{j=1}^{25} \frac{1}{j+\sum_{i=1}^{2}}\left(x_{i}-a_{i j}\right)\right)^{-1}$ & 2 & {$[-65,65]$} & 1 \\
\hline F15 & $f(x)=\sum_{i=1}^{11}\left[a_{i}-\frac{x_{1}\left(b_{i}^{2}+b_{1} x_{2}\right)}{b^{2}+b_{i} x_{3}+x_{4}}\right]^{2}$ & 4 & {$[-5,5]$} & 0.00030 \\
\hline F16 & $f(x)=4 x_{1}^{2}-2.1 x_{1}^{4}+\frac{1}{3} x_{1}^{6}+x_{1} x_{2}-4 x_{2}^{2}+4 x_{2}^{4}$ & 2 & {$[-5,5]$} & -1.0316 \\
\hline F17 & $f(x)=\left(x_{2}-\frac{51}{4-2} x_{1}^{2}+\frac{5}{2} x_{1}-6\right)^{2}+10\left(1-\frac{1}{8 \pi}\right) \cos x_{1}+10$ & 2 & {$[-5,5]$} & 0.398 \\
\hline F18 & $\begin{array}{l}f(x)=\left[1+\left(x_{1}+x_{2}+1\right)^{2}\left(19-14 x_{1}+3 x_{1}^{2}-14 x_{2}+6 x_{1} x_{2}+3 x_{2}^{2}\right)\right] \times \\
{\left[30+\left(2 x_{1}-3 x_{2}\right)^{2} \times\left(18-32 x_{1}+12 x_{1}^{2}+48 x_{2}-36 x_{1} x_{2}+27 x_{2}^{2}\right)\right]}\end{array}$ & 2 & {$[-2,2]$} & 3 \\
\hline F19 & $f(x)=-\sum_{i=1}^{4} c_{i} \exp \left(-\sum_{i=1}^{3} a_{i j}\left(x_{j}-p_{i j}\right)^{2}\right)$ & 3 & {$[-1,2]$} & -3.86 \\
\hline F20 & $f(x)=-\sum_{i=1}^{4} c_{i} \exp \left(-\sum_{i=1}^{6} a_{i j}\left(x_{j}-p_{i j}\right)^{2}\right)$ & 6 & {$[0,1]$} & -.32 \\
\hline F21 & $f(x)=-\sum_{i=1}^{5}\left[\left(X-a_{i}\right)\left(X-a_{i}\right)^{T}+c_{i}\right]^{-1}$ & 4 & {$[0,1]$} & -10.1532 \\
\hline F22 & $f(x)=-\sum_{i=1}^{7}\left[\left(X-a_{i}\right)\left(X-a_{i}\right)^{T}+c_{i}\right]^{-1} 4$ & 4 & {$[0,1]$} & -10.4028 \\
\hline F23 & $f(x)=-\sum_{i=1}^{10}\left[\left(X-a_{i}\right)\left(X-a_{i}\right)^{T}+c_{i}\right]^{-1 / 4}$ & 4 & {$[0,1]$} & -10.5363 \\
\hline
\end{tabular}

Fig. 4 Details of the used benchmark functions

the unimodal test optimization functions. Second, the results have shown that the LSA achieves better performance in conjunction with all other optimized algorithms in multimodal benchmarking optimization (i.e., F11, F17, F18, F19, and F20). The findings confirmed that the LSA profits from a high exploration search and is not stuck in the Optima neighborhood. In the end, The LSA performance on the composite benchmarking functions demonstrated LSA's dominance in overcoming the optimization problems for larger searching areas.

We concluded that the LSA in tested the used set of functions is a robust algorithm. It got promising results that can attract future researchers to use it in their future research. This algorithm (LSA) can be used to solve various optimization problems and, in the future, can test its performance on different scenarios. This opens the researchers' opportunities and facilitates their job in finding a research path for the future.

Moreover, a statistical ranking test, called the Friedman ranking test, is carried out and shown in Table 4 in order to assess the value of the results obtained by LSA. Table 4 demonstrates all comparative optimization algorithms with the summation, average, and final ranking of their results using all benchmarking functions. The findings in Table 4 indicate the statistically significant performance of the LSA. As shown, the LSA algorithm obtained the first ranking compared with the other algorithms (i.e., WOA, SSA, DA, ALO, and LSA). The SSA obtained the second-ranking, followed by, WOA, ALO, and finally DA. Generally, according to the significant test, the LSA is an efficient algorithm that can be used to solve optimization problems.

The convergence speed is a necessary criterion for analyzing optimization algorithms' performance and investigating their improvement capabilities. To fast and clearly explain the effectiveness and search trend of the studied algorithm (LSA), 23 benchmark functions are chosen as the convergence curves of the LSA algorithm and shown in Fig. 5. In all cases, the convergence rate of the LSA is faster than that of other optimization algorithms (the comparative methods: WOA, SSA, DA, ALO, and LSA). The convergence efficiency is also higher than other comparative methods.

Figure 5 explains the convergence trajectory of LSA and other original algorithms for different 10-dimensional benchmark functions. Based on the convergence curve presented in Fig. 5, we can observe that LSA has a consistent convergence speed in most functions such as in F2, F3, F4, F5, F6, and F710 test functions. At the same time, LSA has better exploratory and exploitative experiences than other original methods. It can produce a more constant efficacy by adjusting these search strategies to obtain the global optimum quickly. 
Table 2 Results of the comparative methods using the benchmark functions (F1-F13)

\begin{tabular}{|c|c|c|c|c|c|c|}
\hline Fun & Measure & WOA & SSA & DA & ALO & LSA \\
\hline \multirow[t]{4}{*}{$\mathrm{F} 1$} & Worst & $1.63872 \mathrm{E}-21$ & $1.27467 \mathrm{E}-03$ & $3.37785 \mathrm{E}+03$ & $1.30810 \mathrm{E}-02$ & $1.70140 \mathrm{E}-14$ \\
\hline & Mean & $3.27748 \mathrm{E}-22$ & $2.72113 \mathrm{E}-04$ & $1.34306 \mathrm{E}+03$ & $2.98236 \mathrm{E}-03$ & $3.72979 \mathrm{E}-15$ \\
\hline & Best & $3.49090 \mathrm{E}-38$ & $1.56200 \mathrm{E}-06$ & $9.71815 \mathrm{E}+01$ & $3.99084 \mathrm{E}-05$ & $4.01054 \mathrm{E}-17$ \\
\hline & STD & $7.32857 \mathrm{E}-22$ & $5.60803 \mathrm{E}-04$ & $1.29450 \mathrm{E}+03$ & $5.67247 \mathrm{E}-03$ & $7.43492 \mathrm{E}-15$ \\
\hline \multirow[t]{4}{*}{$\mathrm{F} 2$} & Worst & $9.69461 \mathrm{E}-22$ & $5.02176 \mathrm{E}+00$ & $3.78117 \mathrm{E}+01$ & $3.30577 \mathrm{E}+01$ & $1.89200 \mathrm{E}-09$ \\
\hline & Mean & $2.04331 \mathrm{E}-22$ & $1.90182 \mathrm{E}+00$ & $1.90137 \mathrm{E}+01$ & $1.39253 \mathrm{E}+01$ & $1.05850 \mathrm{E}-09$ \\
\hline & Best & $4.03449 \mathrm{E}-37$ & $5.61137 \mathrm{E}-01$ & $5.48083 \mathrm{E}+00$ & $3.61951 \mathrm{E}+00$ & $4.27647 \mathrm{E}-10$ \\
\hline & STD & $4.28315 \mathrm{E}-22$ & $1.82671 \mathrm{E}+00$ & $1.38083 \mathrm{E}+01$ & $1.16047 \mathrm{E}+01$ & $5.96391 \mathrm{E}-10$ \\
\hline \multirow[t]{4}{*}{ F3 } & Worst & $8.80901 \mathrm{E}+03$ & $4.43494 \mathrm{E}+02$ & $1.72952 \mathrm{E}+04$ & $6.10748 \mathrm{E}+03$ & $7.16532 \mathrm{E}-05$ \\
\hline & Mean & $5.31393 \mathrm{E}+03$ & $2.35148 \mathrm{E}+02$ & $9.83613 \mathrm{E}+03$ & $4.58490 \mathrm{E}+03$ & $1.77198 \mathrm{E}-05$ \\
\hline & Best & $1.94803 \mathrm{E}+03$ & $2.21755 \mathrm{E}+01$ & $7.96763 \mathrm{E}+02$ & $8.44580 \mathrm{E}+02$ & $2.70804 \mathrm{E}-07$ \\
\hline & STD & $2.61568 \mathrm{E}+03$ & $1.89883 \mathrm{E}+02$ & $6.11689 \mathrm{E}+03$ & $2.13226 \mathrm{E}+03$ & $3.05019 \mathrm{E}-05$ \\
\hline \multirow[t]{4}{*}{ F4 } & Worst & $2.76946 \mathrm{E}+01$ & $1.24373 \mathrm{E}+01$ & $4.00126 \mathrm{E}+01$ & $4.39194 \mathrm{E}+01$ & $5.72820 \mathrm{E}-04$ \\
\hline & Mean & $1.33441 \mathrm{E}+01$ & $4.08523 \mathrm{E}+00$ & $2.28472 \mathrm{E}+01$ & $2.37599 \mathrm{E}+01$ & $1.28306 \mathrm{E}-04$ \\
\hline & Best & $5.03594 \mathrm{E}+00$ & $2.39606 \mathrm{E}-01$ & $9.79313 \mathrm{E}+00$ & $7.06860 \mathrm{E}+00$ & $3.16687 \mathrm{E}-06$ \\
\hline & STD & $8.94954 \mathrm{E}+00$ & $4.88031 \mathrm{E}+00$ & $1.18594 \mathrm{E}+01$ & $1.35677 \mathrm{E}+01$ & $2.48800 \mathrm{E}-04$ \\
\hline \multirow[t]{4}{*}{ F5 } & Worst & $8.96676 \mathrm{E}+00$ & $2.02445 \mathrm{E}+04$ & $4.45533 \mathrm{E}+05$ & $2.39373 \mathrm{E}+04$ & $8.92989 \mathrm{E}+00$ \\
\hline & Mean & $8.87146 \mathrm{E}+00$ & $6.80138 \mathrm{E}+03$ & $2.13497 \mathrm{E}+05$ & $6.79125 \mathrm{E}+03$ & $7.53360 \mathrm{E}+00$ \\
\hline & Best & $8.74429 \mathrm{E}+00$ & $2.31821 \mathrm{E}+01$ & $4.30979 \mathrm{E}+04$ & $9.56076 \mathrm{E}+00$ & $5.63693 \mathrm{E}+00$ \\
\hline & STD & $1.10274 \mathrm{E}-01$ & $9.11303 \mathrm{E}+03$ & $2.07227 \mathrm{E}+05$ & $9.78640 \mathrm{E}+03$ & $1.34431 \mathrm{E}+00$ \\
\hline \multirow[t]{4}{*}{ F6 } & Worst & $1.33361 \mathrm{E}+00$ & $3.71652 \mathrm{E}-05$ & $2.43169 \mathrm{E}+03$ & $2.63156 \mathrm{E}-01$ & $7.54230 \mathrm{E}-01$ \\
\hline & Mean & $9.49067 \mathrm{E}-01$ & $1.23397 \mathrm{E}-05$ & $1.18058 \mathrm{E}+03$ & $5.93937 \mathrm{E}-02$ & $4.50541 \mathrm{E}-01$ \\
\hline & Best & $6.17025 \mathrm{E}-01$ & $8.09793 \mathrm{E}-09$ & $7.11157 \mathrm{E}+02$ & $8.54025 \mathrm{E}-04$ & $3.61411 \mathrm{E}-05$ \\
\hline & STD & $3.39831 \mathrm{E}-01$ & $1.51839 \mathrm{E}-05$ & $7.40765 \mathrm{E}+02$ & $1.14044 \mathrm{E}-01$ & $3.26953 \mathrm{E}-01$ \\
\hline \multirow[t]{4}{*}{ F7 } & Worst & $1.36352 \mathrm{E}-02$ & $1.41798 \mathrm{E}-01$ & $1.22561 \mathrm{E}+00$ & $1.25315 \mathrm{E}+00$ & $1.31271 \mathrm{E}-02$ \\
\hline & Mean & $6.22220 \mathrm{E}-03$ & $9.24312 \mathrm{E}-02$ & $5.44345 \mathrm{E}-01$ & $6.65214 \mathrm{E}-01$ & $8.41172 \mathrm{E}-03$ \\
\hline & Best & $1.44522 \mathrm{E}-04$ & $5.69950 \mathrm{E}-02$ & $1.48256 \mathrm{E}-02$ & $2.36137 \mathrm{E}-01$ & $1.63851 \mathrm{E}-03$ \\
\hline & STD & $6.64662 \mathrm{E}-03$ & $3.72186 \mathrm{E}-02$ & $5.71243 \mathrm{E}-01$ & $3.99433 \mathrm{E}-01$ & $4.60452 \mathrm{E}-03$ \\
\hline \multirow[t]{4}{*}{ F8 } & Worst & $-2.19548 \mathrm{E}+03$ & $-2.28072 \mathrm{E}+03$ & $-1.42584 \mathrm{E}+03$ & $-1.80589 \mathrm{E}+03$ & $-1.33460 \mathrm{E}+03$ \\
\hline & Mean & $-3.20496 \mathrm{E}+03$ & $-2.54953 \mathrm{E}+03$ & $-1.96757 \mathrm{E}+03$ & $-1.92666 \mathrm{E}+03$ & $-1.91794 \mathrm{E}+03$ \\
\hline & Best & $-4.18710 \mathrm{E}+03$ & $-2.78632 E+03$ & $-2.30416 \mathrm{E}+03$ & $-2.17279 \mathrm{E}+03$ & $-2.31329 \mathrm{E}+03$ \\
\hline & STD & $9.18877 \mathrm{E}+02$ & $2.46459 \mathrm{E}+02$ & $3.84747 \mathrm{E}+02$ & $1.49804 \mathrm{E}+02$ & $3.76912 \mathrm{E}+02$ \\
\hline \multirow[t]{4}{*}{ F9 } & Worst & $2.84217 \mathrm{E}-14$ & $4.57680 \mathrm{E}+01$ & $8.30512 \mathrm{E}+01$ & $5.57175 \mathrm{E}+01$ & $5.33526 \mathrm{E}+00$ \\
\hline & Mean & $8.52651 \mathrm{E}-15$ & $3.08437 \mathrm{E}+01$ & $6.19974 \mathrm{E}+01$ & $3.78265 \mathrm{E}+01$ & $2.85754 \mathrm{E}+00$ \\
\hline & Best & $0.00000 \mathrm{E}+00$ & $2.08941 \mathrm{E}+01$ & $3.85114 \mathrm{E}+01$ & $1.49245 \mathrm{E}+01$ & $8.81073 \mathrm{E}-13$ \\
\hline & STD & $1.27106 \mathrm{E}-14$ & $9.77390 \mathrm{E}+00$ & $1.65942 \mathrm{E}+01$ & $1.68306 \mathrm{E}+01$ & $2.23865 \mathrm{E}+00$ \\
\hline \multirow[t]{4}{*}{ F10 } & Worst & $6.83009 \mathrm{E}-13$ & $3.57425 \mathrm{E}+00$ & $1.37259 \mathrm{E}+01$ & $1.60192 \mathrm{E}+01$ & $1.16317 \mathrm{E}-07$ \\
\hline & Mean & $1.46549 \mathrm{E}-13$ & $2.25819 \mathrm{E}+00$ & $1.21491 \mathrm{E}+01$ & $1.44427 \mathrm{E}+01$ & $2.65665 \mathrm{E}-08$ \\
\hline & Best & $4.44089 \mathrm{E}-15$ & $4.98126 \mathrm{E}-05$ & $8.59347 \mathrm{E}+00$ & $1.34482 \mathrm{E}+01$ & $9.87108 \mathrm{E}-10$ \\
\hline & STD & $2.99968 \mathrm{E}-13$ & $1.34663 \mathrm{E}+00$ & $2.10686 \mathrm{E}+00$ & $9.64990 \mathrm{E}-01$ & $5.03235 \mathrm{E}-08$ \\
\hline \multirow[t]{4}{*}{ F11 } & Worst & $1.11022 \mathrm{E}-16$ & $3.51766 \mathrm{E}-01$ & $9.14921 \mathrm{E}+01$ & $3.52720 \mathrm{E}-01$ & $1.55423 \mathrm{E}-01$ \\
\hline & Mean & $2.22045 \mathrm{E}-17$ & $1.94064 \mathrm{E}-01$ & $2.34966 \mathrm{E}+01$ & $2.17935 \mathrm{E}-01$ & $8.35621 \mathrm{E}-02$ \\
\hline & Best & $0.00000 \mathrm{E}+00$ & $9.14368 \mathrm{E}-02$ & $4.02841 \mathrm{E}+00$ & $8.72043 \mathrm{E}-02$ & $1.11022 \mathrm{E}-15$ \\
\hline & STD & $4.96507 \mathrm{E}-17$ & $1.18032 \mathrm{E}-01$ & $3.80861 \mathrm{E}+01$ & $1.00524 \mathrm{E}-01$ & $5.78866 \mathrm{E}-02$ \\
\hline \multirow[t]{4}{*}{ F12 } & Worst & $1.58775 \mathrm{E}+00$ & $1.45162 \mathrm{E}+01$ & $1.55574 \mathrm{E}+03$ & $2.24363 \mathrm{E}+01$ & $8.66130 \mathrm{E}-02$ \\
\hline & Mean & $4.87358 \mathrm{E}-01$ & $7.07601 \mathrm{E}+00$ & $3.22413 \mathrm{E}+02$ & $1.82796 \mathrm{E}+01$ & $5.02900 \mathrm{E}-02$ \\
\hline & Best & $3.48445 \mathrm{E}-02$ & $1.66682 \mathrm{E}+00$ & $1.22886 \mathrm{E}+01$ & $1.16935 \mathrm{E}+01$ & $2.07921 \mathrm{E}-02$ \\
\hline & STD & $6.34567 \mathrm{E}-01$ & $5.02364 \mathrm{E}+00$ & $6.89457 \mathrm{E}+02$ & $4.79576 \mathrm{E}+00$ & $2.47617 \mathrm{E}-02$ \\
\hline
\end{tabular}


Table 2 (continued)

\begin{tabular}{|c|c|c|c|c|c|c|}
\hline Fun & Measure & WOA & SSA & DA & ALO & LSA \\
\hline \multirow[t]{4}{*}{ F13 } & Worst & $7.32408 \mathrm{E}-01$ & $9.41551 \mathrm{E}+00$ & $4.18515 \mathrm{E}+06$ & $2.10237 \mathrm{E}+01$ & $7.49187 \mathrm{E}-01$ \\
\hline & Mean & $5.62346 \mathrm{E}-01$ & $1.92739 \mathrm{E}+00$ & $8.37725 \mathrm{E}+05$ & $1.57130 \mathrm{E}+01$ & $5.45405 \mathrm{E}-01$ \\
\hline & Best & $3.93234 \mathrm{E}-01$ & $1.46030 \mathrm{E}-02$ & $6.05468 \mathrm{E}+00$ & $9.64520 \mathrm{E}+00$ & $4.15657 \mathrm{E}-01$ \\
\hline & STD & $1.44274 \mathrm{E}-01$ & $4.18646 \mathrm{E}+00$ & $1.87127 \mathrm{E}+06$ & $4.11582 \mathrm{E}+00$ & $1.24554 \mathrm{E}-01$ \\
\hline
\end{tabular}

Table 3 Results of the comparative methods using the benchmark functions (F14-F23)

\begin{tabular}{|c|c|c|c|c|c|c|}
\hline Fun & Measure & WOA & SSA & DA & ALO & LSA \\
\hline \multirow[t]{4}{*}{ F14 } & Worst & $1.26705 \mathrm{E}+01$ & $1.07632 \mathrm{E}+01$ & $1.26705 \mathrm{E}+01$ & $2.29006 \mathrm{E}+01$ & $1.17187 \mathrm{E}+01$ \\
\hline & Mean & $8.80505 \mathrm{E}+00$ & $5.31404 \mathrm{E}+00$ & $7.45534 \mathrm{E}+00$ & $1.28941 \mathrm{E}+01$ & $6.10535 \mathrm{E}+00$ \\
\hline & Best & $1.99204 \mathrm{E}+00$ & $1.99203 \mathrm{E}+00$ & $3.96825 \mathrm{E}+00$ & $2.98211 \mathrm{E}+00$ & $2.98211 \mathrm{E}+00$ \\
\hline & STD & $4.70124 \mathrm{E}+00$ & $4.17255 \mathrm{E}+00$ & $4.35789 \mathrm{E}+00$ & $9.74117 \mathrm{E}+00$ & $3.38725 \mathrm{E}+00$ \\
\hline \multirow[t]{4}{*}{ F15 } & Worst & $8.17270 \mathrm{E}-03$ & $5.68654 \mathrm{E}-02$ & $9.87799 \mathrm{E}-02$ & $1.17795 \mathrm{E}-02$ & $2.03884 \mathrm{E}-02$ \\
\hline & Mean & $2.20572 \mathrm{E}-03$ & $1.18984 \mathrm{E}-02$ & $4.95913 \mathrm{E}-02$ & $4.08695 \mathrm{E}-03$ & $5.13515 \mathrm{E}-03$ \\
\hline & Best & $3.10563 \mathrm{E}-04$ & $4.39994 \mathrm{E}-04$ & $1.60004 \mathrm{E}-03$ & $1.88228 \mathrm{E}-03$ & $8.15861 \mathrm{E}-04$ \\
\hline & STD & $3.34770 \mathrm{E}-03$ & $2.51376 \mathrm{E}-02$ & $4.49749 \mathrm{E}-02$ & $4.31044 \mathrm{E}-03$ & $8.53479 \mathrm{E}-03$ \\
\hline \multirow[t]{4}{*}{ F16 } & Worst & $-1.03162 \mathrm{E}+00$ & $-1.03163 \mathrm{E}+00$ & $-2.09160 \mathrm{E}-01$ & $-1.03163 \mathrm{E}+00$ & $-1.03163 \mathrm{E}+00$ \\
\hline & Mean & $-1.03163 \mathrm{E}+00$ & $-1.03163 \mathrm{E}+00$ & $-8.66447 \mathrm{E}-01$ & $-1.03163 \mathrm{E}+00$ & $-1.03163 \mathrm{E}+00$ \\
\hline & Best & $-1.03163 \mathrm{E}+00$ & $-1.03163 \mathrm{E}+00$ & $-1.03163 \mathrm{E}+00$ & $-1.03163 \mathrm{E}+00$ & $-1.03163 \mathrm{E}+00$ \\
\hline & STD & $3.03538 \mathrm{E}-06$ & $2.61623 \mathrm{E}-07$ & $3.67437 \mathrm{E}-01$ & $1.74810 \mathrm{E}-12$ & $1.19070 \mathrm{E}-13$ \\
\hline \multirow[t]{4}{*}{ F17 } & Worst & $4.04203 \mathrm{E}-01$ & $3.97935 \mathrm{E}-01$ & $2.70539 \mathrm{E}+00$ & $3.97887 \mathrm{E}-01$ & $3.97887 \mathrm{E}-01$ \\
\hline & Mean & $4.01289 \mathrm{E}-01$ & $3.97899 \mathrm{E}-01$ & $1.33543 \mathrm{E}+00$ & $3.97887 \mathrm{E}-01$ & $3.97887 \mathrm{E}-01$ \\
\hline & Best & $3.98922 \mathrm{E}-01$ & $3.97887 \mathrm{E}-01$ & $3.97895 \mathrm{E}-01$ & $3.97887 \mathrm{E}-01$ & $3.97887 \mathrm{E}-01$ \\
\hline & STD & $2.31790 \mathrm{E}-03$ & $2.01192 \mathrm{E}-05$ & $1.25093 \mathrm{E}+00$ & $8.80930 \mathrm{E}-13$ & $5.79254 \mathrm{E}-13$ \\
\hline \multirow[t]{4}{*}{ F18 } & Worst & $3.02789 \mathrm{E}+01$ & $8.40018 \mathrm{E}+01$ & $3.00635 \mathrm{E}+02$ & $3.00000 \mathrm{E}+00$ & $3.00000 \mathrm{E}+00$ \\
\hline & Mean & $1.11371 \mathrm{E}+01$ & $3.54027 \mathrm{E}+01$ & $7.87273 \mathrm{E}+01$ & $3.00000 \mathrm{E}+00$ & $3.00000 \mathrm{E}+00$ \\
\hline & Best & $3.00976 \mathrm{E}+00$ & $3.00184 \mathrm{E}+00$ & $3.00000 \mathrm{E}+00$ & $3.00000 \mathrm{E}+00$ & $3.00000 \mathrm{E}+00$ \\
\hline & STD & $1.21617 \mathrm{E}+01$ & $4.43641 \mathrm{E}+01$ & $1.28913 \mathrm{E}+02$ & $2.59656 \mathrm{E}-12$ & $1.79368 \mathrm{E}-13$ \\
\hline \multirow[t]{4}{*}{ F19 } & Worst & $-3.73202 \mathrm{E}+00$ & $-3.85928 \mathrm{E}+00$ & $-3.51466 \mathrm{E}+00$ & $-3.86265 \mathrm{E}+00$ & $-3.85690 \mathrm{E}+00$ \\
\hline & Mean & $-3.80523 \mathrm{E}+00$ & $-3.86140 \mathrm{E}+00$ & $-3.72996 \mathrm{E}+00$ & $-3.86273 \mathrm{E}+00$ & $-3.86159 \mathrm{E}+00$ \\
\hline & Best & $-3.85490 \mathrm{E}+00$ & $-3.86259 \mathrm{E}+00$ & $-3.86116 \mathrm{E}+00$ & $-3.86278 \mathrm{E}+00$ & $-3.86278 \mathrm{E}+00$ \\
\hline & STD & $5.00873 \mathrm{E}-02$ & $1.59998 \mathrm{E}-03$ & $1.35628 \mathrm{E}-01$ & $6.49532 \mathrm{E}-05$ & $2.62272 \mathrm{E}-03$ \\
\hline \multirow[t]{4}{*}{$\mathrm{F} 20$} & Worst & $-1.01242 \mathrm{E}+00$ & $-2.88897 \mathrm{E}+00$ & $-3.03326 \mathrm{E}+00$ & $-3.17335 \mathrm{E}+00$ & $-3.11804 \mathrm{E}+00$ \\
\hline & Mean & $-2.49355 \mathrm{E}+00$ & $-3.20255 \mathrm{E}+00$ & $-3.10956 \mathrm{E}+00$ & $-3.29227 \mathrm{E}+00$ & $-3.21866 \mathrm{E}+00$ \\
\hline & Best & $-3.13477 \mathrm{E}+00$ & $-3.32196 \mathrm{E}+00$ & $-3.19048 \mathrm{E}+00$ & $-3.32200 \mathrm{E}+00$ & $-3.32200 \mathrm{E}+00$ \\
\hline & STD & $8.78410 \mathrm{E}-01$ & $1.89124 \mathrm{E}-01$ & $5.75392 \mathrm{E}-02$ & $6.64741 \mathrm{E}-02$ & $9.87709 \mathrm{E}-02$ \\
\hline \multirow[t]{4}{*}{ F21 } & Worst & $-3.50654 \mathrm{E}-01$ & $-2.68154 \mathrm{E}+00$ & $-8.83871 \mathrm{E}-01$ & $-2.68286 \mathrm{E}+00$ & $-5.05520 \mathrm{E}+00$ \\
\hline & Mean & $-2.75659 \mathrm{E}+00$ & $-7.64080 \mathrm{E}+00$ & $-4.13049 \mathrm{E}+00$ & $-6.61993 \mathrm{E}+00$ & $-8.12311 \mathrm{E}+00$ \\
\hline & Best & $-4.89037 \mathrm{E}+00$ & $-1.01495 \mathrm{E}+01$ & $-9.97581 E+00$ & $-1.01532 \mathrm{E}+01$ & $-1.01532 \mathrm{E}+01$ \\
\hline & STD & $2.04718 \mathrm{E}+00$ & $3.53349 \mathrm{E}+00$ & $3.51191 \mathrm{E}+00$ & $3.36769 \mathrm{E}+00$ & $2.77986 \mathrm{E}+00$ \\
\hline \multirow[t]{4}{*}{$\mathrm{F} 22$} & Worst & $-3.73710 \mathrm{E}-01$ & $-5.08753 \mathrm{E}+00$ & $-3.62917 \mathrm{E}+00$ & $-2.75193 \mathrm{E}+00$ & $-5.08767 \mathrm{E}+00$ \\
\hline & Mean & $-2.07645 \mathrm{E}+00$ & $-9.33375 \mathrm{E}+00$ & $-4.94536 \mathrm{E}+00$ & $-7.80969 \mathrm{E}+00$ & $-8.27683 \mathrm{E}+00$ \\
\hline & Best & $-4.30040 \mathrm{E}+00$ & $-1.03988 \mathrm{E}+01$ & $-9.65440 \mathrm{E}+00$ & $-1.04029 \mathrm{E}+01$ & $-1.04029 \mathrm{E}+01$ \\
\hline & STD & $2.02881 \mathrm{E}+00$ & $2.37371 \mathrm{E}+00$ & $2.63970 \mathrm{E}+00$ & $3.64572 \mathrm{E}+00$ & $2.91129 \mathrm{E}+00$ \\
\hline \multirow[t]{4}{*}{$\mathrm{F} 23$} & Worst & $-9.43015 \mathrm{E}-01$ & $-2.42062 \mathrm{E}+00$ & $-9.88163 \mathrm{E}-01$ & $-2.42734 \mathrm{E}+00$ & $-2.42173 \mathrm{E}+00$ \\
\hline & Mean & $-3.26663 \mathrm{E}+00$ & $-7.82678 \mathrm{E}+00$ & $-5.68236 \mathrm{E}+00$ & $-6.04134 \mathrm{E}+00$ & $-6.30827 \mathrm{E}+00$ \\
\hline & Best & $-4.74424 \mathrm{E}+00$ & $-1.05325 \mathrm{E}+01$ & $-1.04054 \mathrm{E}+01$ & $-1.05364 \mathrm{E}+01$ & $-1.05364 \mathrm{E}+01$ \\
\hline & STD & $1.63068 \mathrm{E}+00$ & $3.82106 \mathrm{E}+00$ & $3.89274 \mathrm{E}+00$ & $4.13487 \mathrm{E}+00$ & $3.99863 \mathrm{E}+00$ \\
\hline
\end{tabular}


Table 4 Statistical analysis results of the comparative methods using all benchmark functions (F1-F23)

\begin{tabular}{|c|c|c|c|c|c|}
\hline Fun & WOA & SSA & DA & ALO & LSA \\
\hline F1 & 1 & 3 & 5 & 4 & 2 \\
\hline $\mathrm{F} 2$ & 1 & 3 & 5 & 4 & 2 \\
\hline F3 & 4 & 2 & 5 & 3 & 1 \\
\hline $\mathrm{F} 4$ & 3 & 2 & 4 & 5 & 1 \\
\hline F5 & 2 & 4 & 5 & 3 & 1 \\
\hline F6 & 4 & 1 & 5 & 2 & 3 \\
\hline F7 & 1 & 3 & 4 & 5 & 2 \\
\hline F8 & 1 & 2 & 3 & 4 & 5 \\
\hline F9 & 1 & 3 & 5 & 4 & 2 \\
\hline F10 & 1 & 3 & 4 & 5 & 2 \\
\hline F11 & 1 & 3 & 5 & 4 & 2 \\
\hline F12 & 2 & 3 & 5 & 4 & 1 \\
\hline F13 & 2 & 3 & 5 & 4 & 1 \\
\hline F14 & 4 & 2 & 3 & 5 & 1 \\
\hline F15 & 1 & 3 & 5 & 2 & 4 \\
\hline F16 & 4 & 1 & 5 & 2 & 3 \\
\hline F17 & 4 & 1 & 5 & 2 & 3 \\
\hline F18 & 3 & 1 & 5 & 2 & 4 \\
\hline F19 & 4 & 3 & 5 & 1 & 2 \\
\hline F20 & 5 & 2 & 4 & 1 & 3 \\
\hline $\mathrm{F} 21$ & 5 & 1 & 4 & 3 & 2 \\
\hline F22 & 5 & 2 & 4 & 3 & 1 \\
\hline $\mathrm{F} 23$ & 5 & 2 & 4 & 3 & 1 \\
\hline Summation & 64 & 53 & 104 & 75 & 49 \\
\hline Mean rank & 2.782608696 & 2.304347826 & 4.52173913 & 3.260869565 & 2.130434783 \\
\hline Final ranking & 3 & 2 & 5 & 4 & 1 \\
\hline
\end{tabular}

\subsection{Real-word engineering design problems}

In this section, two real-world engineering problems (i.e., Tension/compression spring design and Pressure vessel design problems) are tested to show the performance of the studied LSA. The obtained results are compared with other well-known optimization methods published in the literature.

\subsubsection{Problem 1: tension/compression spring design}

The problem of tension/compression spring design is given to degrade the entire weight of a given spring [42]. Three variables are examined in this problem: (1) wire diameter $(d)$, (2) mean coil diameter $(D)$, and (3) the number of active coils $(N)$, as presented in Fig. 6 . The result of the comparative methods are given in Table 5. The comparative methods are HHO [109], PSO [110], RO [51], HS [111], ES [112], BA [113], MFO [114], and LSA [64]. The results in Table 5 showed that the LSA got comparative results compared to other published methods. As shown in Fig. 7, the LSA reached the optimal solution very fast in the first iterations, which reflect the ability of the LSA in solving the complex real-world problems, especially, in solving the Tension/compression spring design problem.

\subsubsection{Problem 2: pressure vessel design}

The problem of pressure vessel design is given to degrade the entire weight of a given pressure vessel [115]. Four variables are examined in this problem: (1) width of the shell $\left(T_{S}\right),(2)$ the width of the head $\left(T_{h}\right)$, (3) internal radius $(R)$, and (4) height of the cylindrical part without studying the head $(L)$, as shown in Fig. 8. The result of the comparative methods are given in Table 6. The comparative methods are HS [116], CPSO [110], CSCA [117], HPSO [118], GSA [119], ACO [120], MVO [48], ES [112], and LSA [64]. The results in Table 6 revealed that the LSA produced also comparative results compared to other published methods. As presented in Fig. 9, the LSA gave the optimal solution early in the first iterations, which shows the strong capability of the LSA in addressing complex realworld problems, especially, in solving the Pressure vessel design problem. 

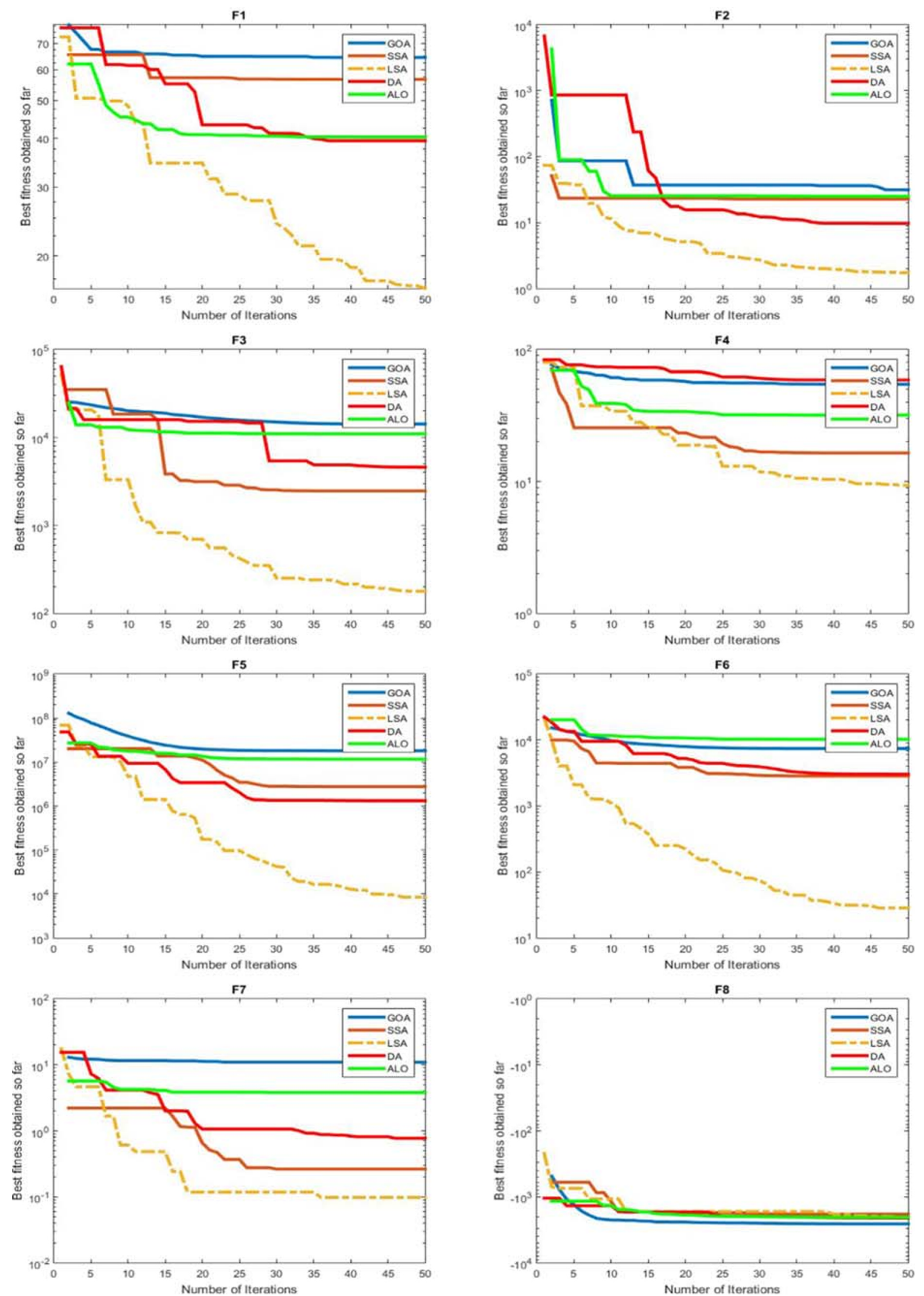

Fig. 5 Convergence behavior of the comparative optimization algorithms on the test functions (F1-F23) 

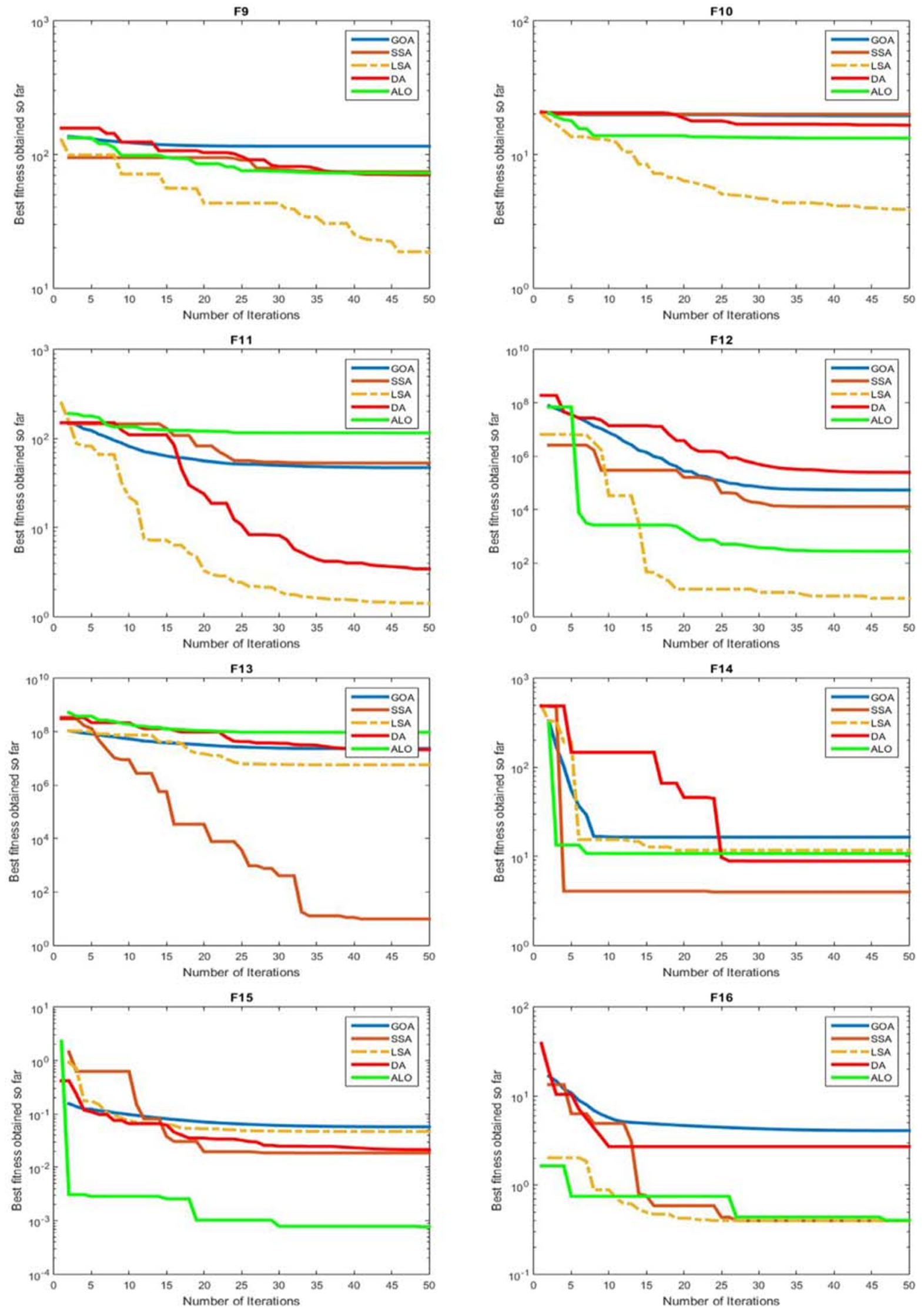

Fig. 5 (continued) 

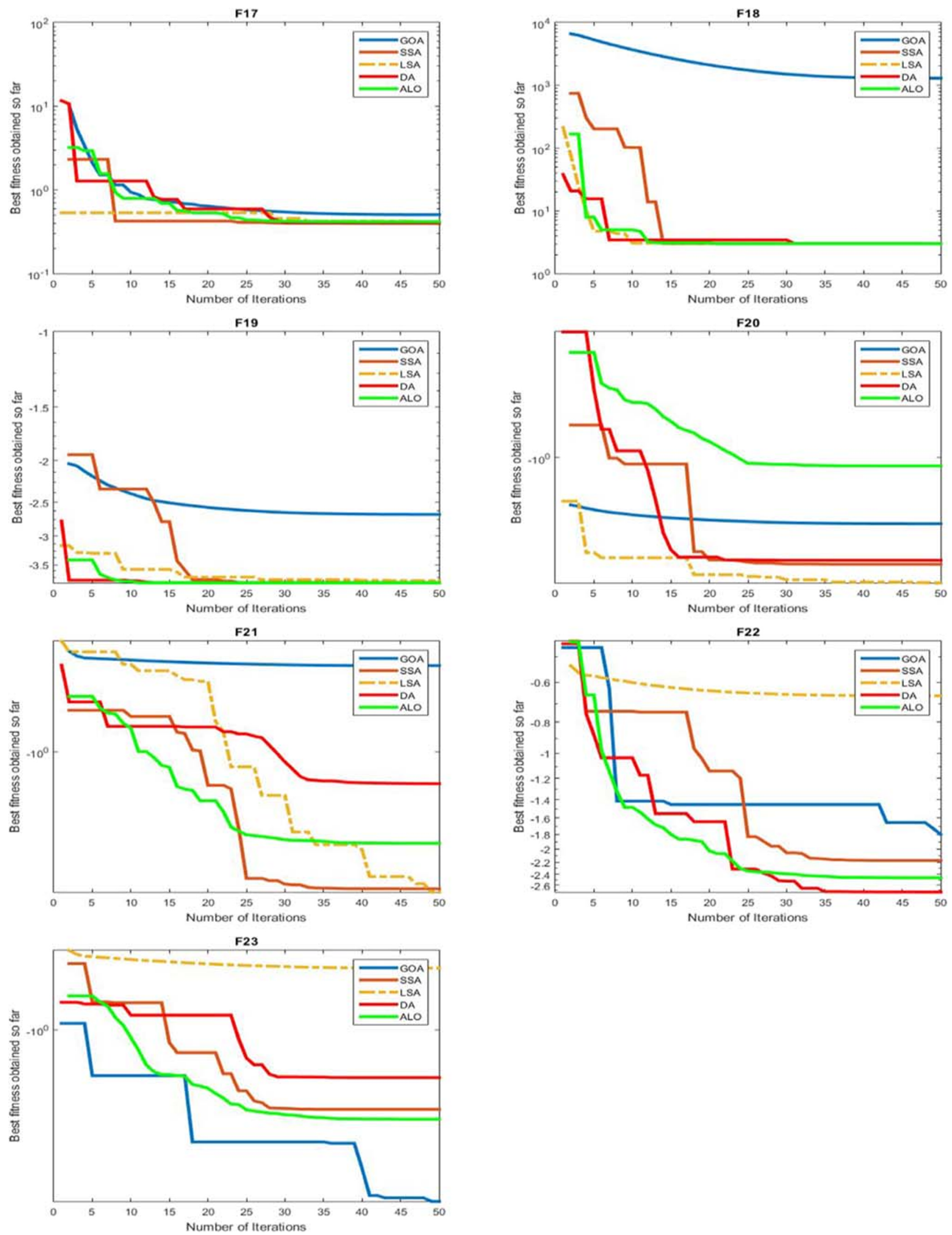

Fig. 5 (continued) 
Fig. 6 Tension/compression spring design problem

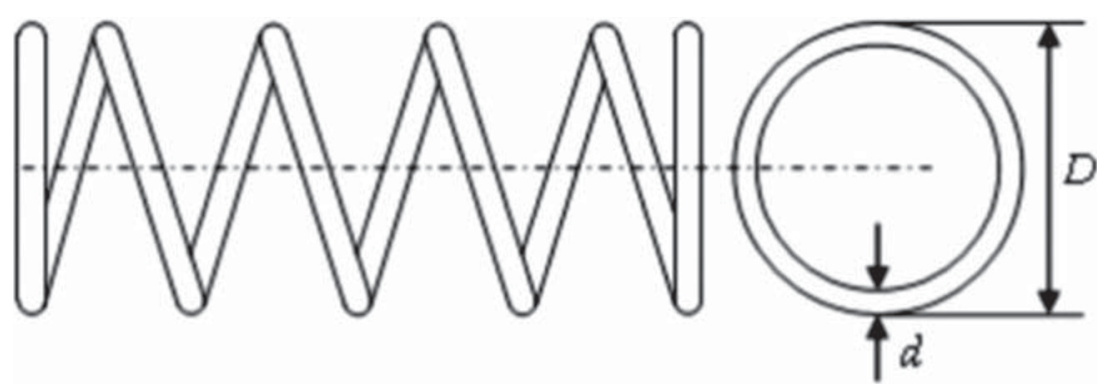

\section{Discussion}

This section presents the theoretical perspectives and evaluation of LSA.

Global numerical problems such as test functions are blended to give near-optimal solutions of a numerical representation by determining the wanted minimum or maximum function value. Due to increasing the complexity of optimization jobs used in many optimization problems such as engineering problems and real-world problems, the development of powerful stochastic methods is shifting much necessary, critical, and essential than before. Over the earlier decennium, several various optimization methods have been used according to different perspectives of biology or nature-life.

The distribution of the addressing rule is classified into a couple of stages, which is the prime advantage of multisolution methods (i.e., stochastic search: exploration and exploitation). The above-mentioned (exploration) indicates a manner where the population (solutions) trend to be developed repeatedly and examine the encouraging areas of the search space as complete as possible. Dissimilarity, the search solutions are controlled or led by the exploitation or intensification to draw close the near-optimal solution obtained in the global search stage.

The advantage of meta-heuristic algorithms is shown for many reasons. The first reason, the benefit of random

Table 5 The algorithms results for the tension/compression spring design problem

\begin{tabular}{lllll}
\hline Algorithm & \multicolumn{2}{l}{ Optimal values for variables } & \multirow{2}{*}{ Optimal } \\
\cline { 2 - 4 } & $d$ & $D$ & $N$ & cost \\
\hline HHO & 0.05197639 & 0.363669510 & 10.89275181 & 0.01266674 \\
PSO & 0.05172800 & 0.357644000 & 11.24454300 & 0.01267470 \\
RO & 0.05137000 & 0.349096000 & 11.76279000 & 0.01267880 \\
HS & 0.05115400 & 0.349871000 & 12.07643200 & 0.01267060 \\
ES & 0.05164300 & 0.355360000 & 11.39792600 & 0.01269800 \\
BA & 0.05169000 & 0.356720000 & 11.28850000 & 0.01267000 \\
MFO & 0.05199446 & 0.364109320 & 10.86842186 & 0.01266690 \\
LSA & 0.05027598 & 0.32367954 & 13.52540953 & 0.012720452 \\
\hline
\end{tabular}

style encourages these algorithms to avert the stuck in local exploitation and focalize to the near-optimal solution. Directly, the aim is not to receive the best solution of the problem solutions but to find the near-optimal solution (with high fitness value within a reasonable running time). The main factor in creating this aim is to make the proper stability across search procedures. Exploration propose is to discover the more promising areas in a complexwide search area. Consequently, the exploitation procedure is become intensified by the local search procedure in a promising area to offer better solutions. The optimal accomplishment and effectiveness of a unique optimization technique in trade-off these techniques, the better ability will be performed. The current meta-heuristic algorithms adjust the balance amongst these two approaches in various approaches. They could be further qualified and adjusted for local or for global search procedures. Two or more optimization techniques are mixed by hybrid its elements to get its essential characteristics together and powerful than each one alone while averting as much as possible their disadvantages and shortcomings. The second cause, the completion of optimization techniques is due to its origin, abilities, simplicity, and balance experimentally.

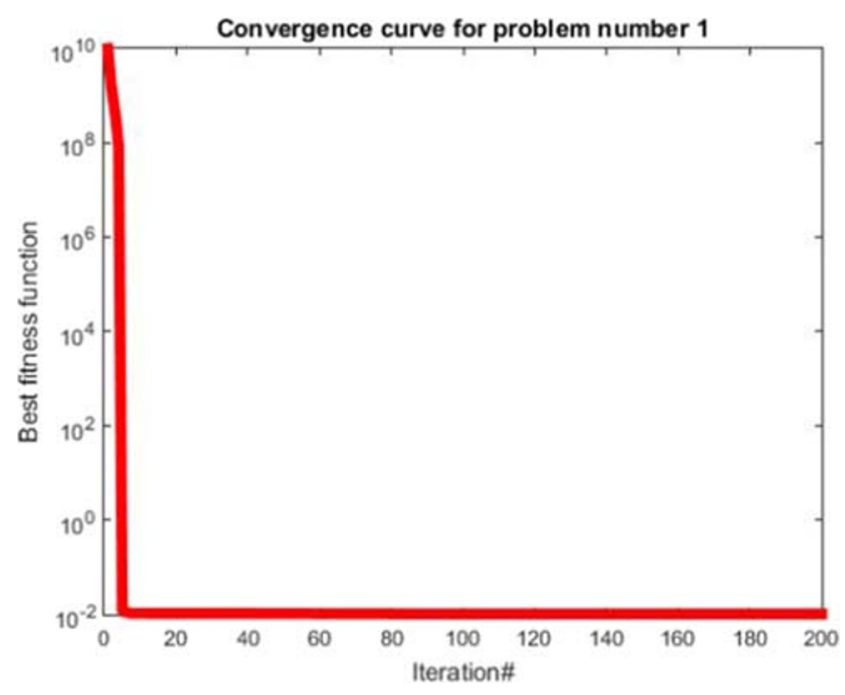

Fig. 7 Curve of the LSA in solving the tension/compression spring design problem 


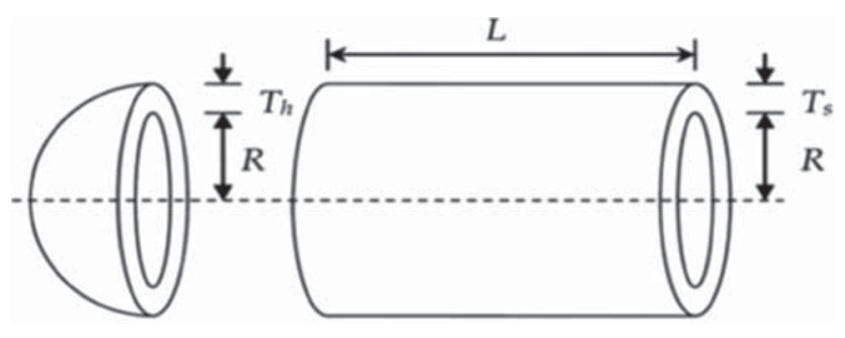

Fig. 8 Pressure vessel design problem

Meta-heuristic optimization algorithms have been employed extensively to tackle complex problems. However, for complex problems, the most generous portion of the optimization techniques still fallen and trapped in local search and be unsuccessful to fulfill the near-global solution. This is the idea of the week of diversification (global search) role (i.e., component) in the applied technique. Several diversification search approaches are used to improve the effectiveness of well-known optimization techniques and serve in stopping the drawbacks. These optimization methods are hybridization and elitism: the survival of an elite as a dominating element in a system.

LSA algorithm has risen exponentially and become a robust mechanism for addressing complex problems, as other optimization methods. It is an artificial intelligence technique, operates by stochastic computational mechanisms, to determine the near-optimal solution for the multidimensional purposes and one-dimensional according to its objective function. The LSA works in a typical style; it is easily implemented and efficiently used in a broad class of domains. The results summarized in this review paper provide evidence and verification of the performance success of the LSA in regards to the effectiveness and accuracy of the got the best result. This support is determined according to examining and analyzing the obtained results among the LSA and recently published optimization techniques.

Table 6 The algorithms results for the pressure vessel design problem

\begin{tabular}{lllllll}
\hline Algorithm & \multicolumn{2}{l}{ Optimal values } & & \multicolumn{2}{c}{ Optimal } \\
\cline { 2 - 5 } & \multicolumn{1}{l}{$T_{s}$} & $T_{h}$ & $R$ & $L$ & \multicolumn{1}{l}{ cost } \\
\hline HS & 1.125000 & 0.625000 & 58.29015 & 43.69268 & 7197.730 \\
CPSO & 0.8125 & 0.4375 & 42.091266 & 176.7465 & 6061.0777 \\
CSCA & 0.8125 & 0.4375 & 42.098411 & 176.63769 & 6059.7340 \\
HPSO & 0.8125 & 0.4375 & 42.0984 & 176.6366 & 6059.7143 \\
GSA & 1.125 & 0.625 & 55.9886598 & 84.4542025 & 8538.8359 \\
ACO & 0.812500 & 0.437500 & 42.098353 & 176.637751 & 6059.7258 \\
MVO & 0.8125 & 0.4375 & 42.090738 & 176.73869 & 6060.8066 \\
ES & 0.8125 & 0.4375 & 42.098087 & 176.640518 & 6059.74560 \\
LSA & 0.81250 & 0.43750 & 42.097398 & 176.65405 & 6059.94634 \\
\hline
\end{tabular}

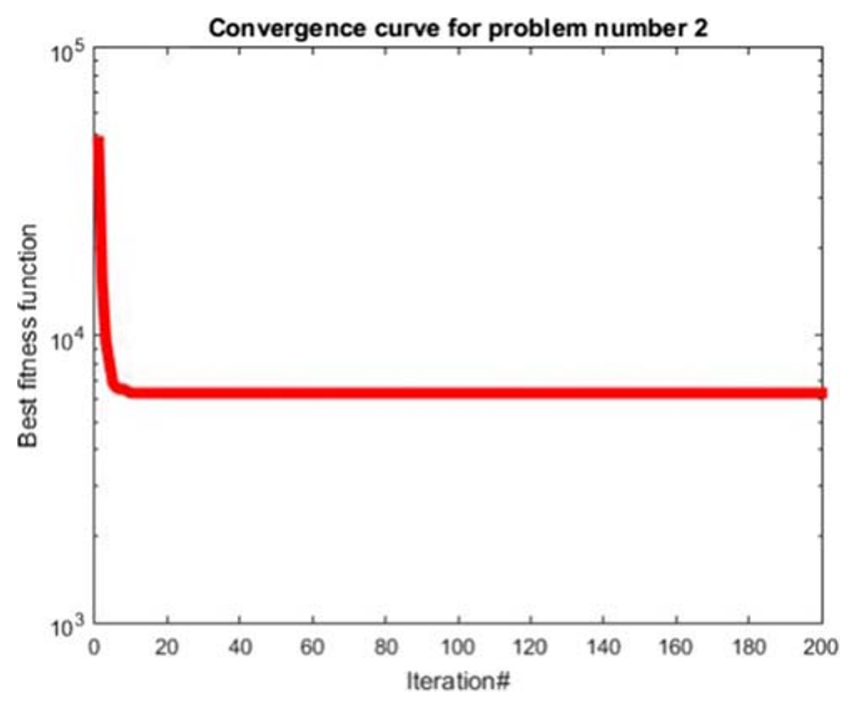

Fig. 9 Curve of the LSA in solving the pressure vessel design problem

Similar to various optimization techniques, LSA holds some benefits (strong points) and few disadvantages (weaknesses). Even though there is no confluence evidence for this optimizer, the final features are summarized in

Table 7 Advantages and disadvantages of LSA

Advantages

- Mixing with other algorithms is remarkably satisfying

- A good convergence speedup

- The accelerated manner in producing excellent solutions

- Suitable for various kinds of optimization difficulties

- An effective global design to explore

- Fitting for a broad search space

- Significant neighborhood search characteristic

- Adaptability, robustness, and scalability are found essential characteristics

- Vital in managing a complete number of determinations

- Have higher feasibility and efficiency in producing global optima

- Lower plainly of stuck in local optima

- Less reliance on initial solutions

- LSA is easy in its idea and implementation associated with other heuristic optimization procedures

- Reasonable execution time

- A few parameter tuning

Disadvantages

- The first suggestion of LSA has been proposed for discrete problems, single-objective problems, and multi-objective problems

- Suffer from premature convergence

- No theoretical converging frame

- Probability distribution changes by generations 
this review to confirm that the LSA competitiveness over other optimization algorithms in regards to convergence stimulated (rate). Table 7 shows the strength (advantages) and weaknesses (disadvantages) of LSA.

The robust application of these algorithms, like LSA, in industry and science, evidences the advantages of swarm techniques in usage. The reasons are because of the advantages of swarm algorithms. Firstly, swarm techniques keep information regarding the search space throughout iterations, whereas such data is rejected by evolutionary algorithms iteration by iteration. Secondly, there are some fewer controlling parameters in swarm algorithms. Thirdly, the swarm algorithm is equipped with fewer operators related to evolutionary algorithms. Finally, swarm techniques benefit from adaptability, which makes them easily applicable to problems in various fields.

The main difficulty of LSA is how to define the probabilistic convergence properties of LSA, which is required to understand the given technique fully. The problem of early convergence (premature convergence) in the LSA typically begins the recovery procedure to be stuck throughout the exploitation search. This effect usually occurs while the solutions divergence decreases, and the solutions cannot avert falling in the local optima. Furthermore, there are considerable potentials for researchers to employ and apply the advantages of LSA to approach the complex industry and any real-world problems.

\section{Conclusion and future works}

A comprehensive research review of the SLA algorithm is given in this work. The primary purpose of this paper is intended at reviewing the variants and applications, and results of the SLA algorithm in all studied classes. According to the collected papers that have been published in the literature, the improved LSA algorithm is the chief style utilized. We additionally obtained all the presented articles from the papers that employed the LSA algorithm, such as in benchmark functions, image processing, machine learning, engineering applications, networks, software engineering, and other problems. Finally, we compared the results of the LSA with other similar optimization algorithms using standard test functions.

Besides that, many researchers mentioned that the LSA algorithm could address various optimization problems such as pattern recognition problems, other engineering problems, clustering optimization problems, intrusion detection problems in wireless networks, and unconstrained optimization problems. In a word, the LSA algorithm is mighty in all the tested problems based on the analysis of the published articles in the literature. In conclusion, there is still a chance or scope for enhancing the performance; the LSA algorithm could be improved into various methods such as hybridization, modification, changed, and modifications based on the demands of the assigned difficulties.

Consequently, the outcome results of this study could be affected by the interested scholars to present several methods for improvement goal by taking into consideration the importance, benefits, or errors of other proposed methods by scholars. For the potential future trends in this domain, we recommend to employ and improve the LSA algorithm with other procedures components for further changes to address various optimization problems.

In future work, we will converge the following aspects:

- Adapting the LSA algorithm to address the unsolved problems by the LSA algorithm before.

- Employing the LSA algorithm to address various multiobjective optimization problems.

- Modifying the LSA algorithm to address various realworld optimization problems such as NP-hard and discrete problems.

- Fusion the LSA algorithm with other different operators to address real-world problems such as NP-hard and discrete problems.

\section{References}

1. Yıldız AR, Yıldız BS, Sait SM, Li X (2019) The harris hawks, grasshopper and multi-verse optimization algorithms for the selection of optimal machining parameters in manufacturing operations. Materials Testing 61:725-733

2. Champasak P, Panagant N, Pholdee N, Bureerat S, Yildiz AR (2020) Self-adaptive many-objective meta-heuristic based on decomposition for many-objective conceptual design of a fixed wing unmanned aerial vehicle. Aerosp Sci Technol 100:105783

3. Kurtuluş E, Yıldız AR, Sait SM, Bureerat S (2020) A novel hybrid harris hawks-simulated annealing algorithm and rbfbased metamodel for design optimization of highway guardrails. Materials Testing 62:251-260

4. Shehab M, Daoud MS, AlMimi HM, Abualigah LM, Khader AT (2019) Hybridising cuckoo search algorithm for extracting the odf maxima in spherical harmonic representation. International Journal of Bio-Inspired Computation 14:190-199

5. Yildiz AR, Abderazek H, Mirjalili S (2019) A comparative study of recent non-traditional methods for mechanical design optimization. Archives of Computational Methods in Engineering $1-18$

6. Beyer H-G, Sendhoff B (2007) Robust optimization-a comprehensive survey. Comput Methods Appl Mech Eng 196:31903218

7. Oliva D, Ewees AA, Aziz MAE, Hassanien AE, Peréz-Cisneros M (2017) A chaotic improved artificial bee colony for parameter estimation of photovoltaic cells. Energies 10:865

8. El Aziz MA, Ewees AA, Hassanien AE, Mudhsh M, Xiong S (2018) Multi-objective whale optimization algorithm for multilevel thresholding segmentation. In: Advances in soft computing and machine learning in image processing, Springer, pp 23-39

9. Coello CAC (2000) Use of a self-adaptive penalty approach for engineering optimization problems. Comput Ind 41:113-127 
10. Knowles JD, Watson RA, Corne DW (2001) Reducing local optima in single-objective problems by multi-objectivization. In: International conference on evolutionary multi-criterion optimization, Springer, pp 269-283

11. Glover FW, Kochenberger GA (2006) Handbook of metaheuristics, vol 57. Springer Science \& Business Media

12. Nesmachnow S (2014) An overview of metaheuristics: accurate and efficient methods for optimisation. International Journal of Metaheuristics 3:320-347

13. Meng Z, Li G, Wang X, Sait SM, Yıldiz AR (2020) A comparative study of metaheuristic algorithms for reliabilitybased design optimization problems. Archives of Computational Methods in Engineering

14. Abualigah LMQ (2019) Feature selection and enhanced krill herd algorithm for text document clustering. Springer

15. Feng Y, Chen H, Li T, Luo C (2020) A novel community detection method based on whale optimization algorithm with evolutionary population. Appl Intell 1-20

16. Goldberg DE (1989) Genetic algorithms in search. Optimization, and Machine Learning

17. Storn R, Price K (1997) Differential evolution-a simple and efficient heuristic for global optimization over continuous spaces. J Glob Optim 11:341-359

18. Koza JR, Koza JR (1992) Genetic programming: on the programming of computers by means of natural selection, vol 1 . MIT Press

19. Askarzadeh A (2014) Bird mating optimizer: an optimization algorithm inspired by bird mating strategies. Commun Nonlinear Sci Numer Simul 19:1213-1228

20. Zou F, Wang L, Hei X, Chen D (2015) Teaching-learning-based optimization with learning experience of other learners and its application. Appl Soft Comput 37:725-736

21. Kumar M, Kulkarni AJ, Satapathy SC (2018) Socio evolution \& learning optimization algorithm: a socio-inspired optimization methodology. Futur Gener Comput Syst 81:252-272

22. Li M, Zhao H, Weng X, Han T (2016) Cognitive behavior optimization algorithm for solving optimization problems. Appl Soft Comput 39:199-222

23. Huan TT, Kulkarni AJ, Kanesan J, Huang CJ, Abraham A (2017) Ideology algorithm: a socio-inspired optimization methodology. Neural Comput \& Applic 28:845-876

24. Al-Betar MA, Alyasseri ZAA, Awadallah MA et al (2020) Coronavirus herd immunity optimizer (CHIO). Neural Comput \& Applic. https://doi.org/10.1007/s00521-020-05296-6

25. Mousavirad SJ, Ebrahimpour-Komleh H (2017) Human mental search: a new population-based metaheuristic optimization algorithm. Appl Intell 47:850-887

26. Liu Z-Z, Chu D-H, Song C, Xue X, Lu B-Y (2016) Social learning optimization (slo) algorithm paradigm and its application in qos-aware cloud service composition. Inf Sci 326:315-333

27. Hassanien AE, Emary E (2018) Swarm intelligence: principles, advances, and applications. CRC Press

28. Kennedy J, Eberhart R (1995) Particle swarm optimization. In: Proceedings of ICNN'95-international conference on neural networks, IEEE, vol 4, pp 1942-1948

29. Dorigo M, Maniezzo V, Colorni A (1996) Ant system: optimization by a colony of cooperating agents. IEEE Trans Syst Man Cybern B (Cybern) 26:29-41

30. Yang K, You X, Liu S, Pan H (2020) A novel ant colony optimization based on game for traveling salesman problem. Appl Intell 1-14

31. Hussien AG, Hassanien AE, Houssein EH (2017) Swarming behaviour of salps algorithm for predicting chemical compound activities. In: 2017 Eighth international conference on intelligent computing and information systems (ICICIS), IEEE, pp 315-320

32. Mirjalili S, Mirjalili SM, Lewis A (2014) Grey wolf optimizer. Adv Eng Softw 69:46-61

33. Cheng M-Y, Prayogo D (2014) Symbiotic organisms search: a new metaheuristic optimization algorithm. Comput Struct 139:98-112

34. Hussien AG, Houssein EH, Hassanien AE (2017) A binary whale optimization algorithm with hyperbolic tangent fitness function for feature selection. In: 2017 Eighth international conference on intelligent computing and information systems (ICICIS), IEEE, pp 166-172

35. Gandomi AH, Alavi AH (2012) Krill herd: a new bio-inspired optimization algorithm. Commun Nonlinear Sci Numer Simul 17:4831-4845

36. Askarzadeh A (2016) A novel metaheuristic method for solving constrained engineering optimization problems: crow search algorithm. Comput Struct 169:1-12

37. Abualigah L, Shehab M, Alshinwan M, Alabool H (2019) Salp swarm algorithm: a comprehensive survey. Neural Comput \& Applic 1-21

38. Cuevas E, Cienfuegos M, ZaldíVar D, Pérez-Cisneros M (2013) A swarm optimization algorithm inspired in the behavior of the social-spider. Expert Syst Appl 40:6374-6384

39. Yang X-S, Deb S (2009) Cuckoo search via lévy flights. In: 2009 World congress on nature \& biologically inspired computing (naBIC), IEEE, pp 210-214

40. Yang X-S (2010) Firefly algorithm, stochastic test functions and design optimisation. arXiv:1003.1409

41. Abualigah L, Diabat A (2020) A novel hybrid antlion optimization algorithm for multi-objective task scheduling problems in cloud computing environments. Clust Comput 1-19

42. Arora S, Singh S (2019) Butterfly optimization algorithm: a novel approach for global optimization. Soft Comput 23:715-734

43. Abualigah L (2020) Multi-verse optimizer algorithm: a comprehensive survey of its results, variants, and applications. Neural Comput \& Applic 1-21

44. Hussien AG, Amin M, Abd El Aziz M (2020) A comprehensive review of moth-flame optimisation: variants, hybrids, and applications. Journal of Experimental \& Theoretical Artificial Intelligence 1-21

45. Shehab M, Abualigah L, Al Hamad H, Alabool H, Alshinwan M, Khasawneh AM (2019) Moth-flame optimization algorithm: variants and applications. Neural Comput \& Applic 1-26

46. Zhao X, Fang Y, Liu L, Li J, Xu M (2020) An improved mothflame optimization algorithm with orthogonal opposition-based learning and modified position updating mechanism of moths for global optimization problems. Appl Intell 1-25

47. Lam AY, Li VO (2009) Chemical-reaction-inspired metaheuristic for optimization. IEEE Trans Evol Comput 14:381-399

48. Mirjalili S, Mirjalili SM, Hatamlou A (2016) Multi-verse optimizer: a nature-inspired algorithm for global optimization. Neural Comput \& Applic 27:495-513

49. Sadollah A, Bahreininejad A, Eskandar H, Hamdi M (2013) Mine blast algorithm: a new population based algorithm for solving constrained engineering optimization problems. Appl Soft Comput 13:2592-2612

50. Kaveh A, Bakhshpoori T (2016) Water evaporation optimization: a novel physically inspired optimization algorithm. Comput Struct 167:69-85

51. Kaveh A, Khayatazad M (2012) A new meta-heuristic method: ray optimization. Comput Struct 112:283-294

52. Kirkpatrick S, Gelatt CD, Vecchi MP (1983) Optimization by simulated annealing. Science 220:671-680 
53. Kaveh A, Dadras A (2017) A novel meta-heuristic optimization algorithm: thermal exchange optimization. Adv Eng Softw 110:69-84

54. Abedinpourshotorban H, Shamsuddin SM, Beheshti Z, Jawawi DN (2016) Electromagnetic field optimization: a physicsinspired metaheuristic optimization algorithm. Swarm and Evolutionary Computation 26:8-22

55. Erol OK, Eksin I (2006) A new optimization method: big bangbig crunch. Adv Eng Softw 37:106-111

56. Zhao W, Wang L, Zhang Z (2019) Atom search optimization and its application to solve a hydrogeologic parameter estimation problem. Knowl-Based Syst 163:283-304

57. Muthiah-Nakarajan V, Noel MM (2016) Galactic swarm optimization: a new global optimization metaheuristic inspired by galactic motion. Appl Soft Comput 38:771-787

58. Doğan B, Ölmez T (2015) A new metaheuristic for numerical function optimization: vortex search algorithm. Inf Sci 293:125-145

59. Glover F (1989) Tabu search — part i. ORSA J Comput 1:190-206

60. Glover F (1990) Tabu search-part ii. ORSA J Comput 2:4-32

61. Lourenço HR, Martin OC, Stützle T (2003) Iterated local search. In: Handbook of metaheuristics, Springer, pp 320-353

62. Voudouris C, Tsang E (1999) Guided local search and its application to the traveling salesman problem. Eur J Oper Res 113:469-499

63. Mladenović N, Hansen P (1997) Variable neighborhood search. Comput Oper Res 24:1097-1100

64. Shareef H, Ibrahim AA, Mutlag AH (2015) Lightning search algorithm. Appl Soft Comput 36:315-333

65. Islam MM, Shareef H, Mohamed A, Wahyudie A (2017) A binary variant of lightning search algorithm: Blsa. Soft Comput 21:2971-2990

66. Islam MM, Shareef H, Mohamed A (2017) Improved approach for electric vehicle rapid charging station placement and sizing using google maps and binary lightning search algorithm. PloS One 12:e0189170

67. Hannan MA, Ali JA, Hussain A, Hasim FH, Amirulddin UAU, Uddin MN, Blaabjerg F (2017) A quantum lightning search algorithm-based fuzzy speed controller for induction motor drive. IEEE Access 6:1214-1223

68. Wong LA, Ling TJ, Ramlee NA (2018) Optimal power quality monitors placement using improved lightning search algorithm. In: 2018 IEEE 7th international conference on power and energy (PECon), IEEE, pp 227-230

69. Hannan MA, Ali JA, Mohamed A, Amirulddin UAU, Tan NML, Uddin MN (2018) Quantum-behaved lightning search algorithm to improve indirect field-oriented fuzzy-pi control for im drive. IEEE Trans Ind Appl 54:3793-3805

70. Sirjani R (2017) Optimal capacitor placement in wind farms by considering harmonics using discrete lightning search algorithm. Sustainability 9:1669

71. Kabalci Y, Kabalci E (2019) Noise insensitive optimal harmonic estimator design with lightning search algorithm. Swarm and Evolutionary Computation 46:219-234

72. Li X, Zhang H (2020) A multi-agent complex network algorithm for multi-objective optimization. Appl Intell 1-28

73. Thangaraj Y, Kuppan R (2017) Multi-objective simultaneous placement of $\mathrm{dg}$ and dstatcom using novel lightning search algorithm. J Appl Res Technol 15:477-491

74. Aljanad A, Mohamed A, Shareef H, Khatib T (2018) A novel method for optimal placement of vehicle-to-grid charging stations in distribution power system using a quantum binary lightning search algorithm. Sustainable Cities and Society $38: 174-183$
75. Jeddi B, Einaddin AH, Kazemzadeh R (2016) Optimal power flow problem considering the cost, loss, and emission by multi-objective electromagnetism-like algorithm. In: 2016 6th conference on thermal power plants (CTPP), IEEE, pp 38-45

76. Abd Ali J, Hannan MA, Mohamed A (2015) A novel quantumbehaved lightning search algorithm approach to improve the fuzzy logic speed controller for an induction motor drive. Energies 8:13112-13136

77. Islam M, Shareef H, Nagrial MH, Rizk J, Hellany A, Khalid SN, et al. (2019) Performance comparison of various probability gate assisted binary lightning search algorithm. IAES Int J Artif Intell 228-236

78. Abualigah LM, Khader AT, Hanandeh ES (2018) Hybrid clustering analysis using improved krill herd algorithm. Appl Intell 48:4047-4071

79. Faris H, Aljarah I, Al-Madi N, Mirjalili S (2016) Optimizing the learning process of feedforward neural networks using lightning search algorithm. International Journal on Artificial Intelligence Tools 25:1650033

80. Syed Nasir S, Jamian JJ, Mustafa MW (2018) Minimizing harmonic distortion impact at distribution system with considering large-scale ev load behaviour using modified lightning search algorithm and pareto-fuzzy approach. Complexity 2018

81. Yousri D, Abd Elaziz M, Oliva D, Abualigah L, Al-qaness MA, Ewees AA (2020) Reliable applied objective for identifying simple and detailed photovoltaic models using modern metaheuristics: comparative study. Energy Convers Manag 223:113279

82. Sirjani R, Shareef H (2016) Parameter extraction of solar cell models using the lightning search algorithm in different weather conditions. Journal of Solar Energy Engineering 138

83. Kumarappan N, Arulraj R et al (2018) Multiple installation of $\mathrm{dg}$ and dstatcom in radial distribution network using lightning search algorithm. In: 2018 International conference on power, energy, control and transmission systems (ICPECTS), IEEE, pp 264-269

84. Abdel-Moamen M, Padhy NP (2003) Optimal power flow incorporating facts devices-bibliography and survey. In: 2003 IEEE PES transmission and distribution conference and exposition (IEEE cat. no. 03CH37495), IEEE, vol 2, pp 669-676

85. Hamanah W, Abido M, Alhems LM (2019) Optimum sizing of hybrid pv, wind, battery and diesel system using lightning search algorithm. Arab J Sci Eng 1-13

86. Muqbel A, Elsayed AH, Abido MA, Mantawy A-A, Al-Awami AT, El-Hawary M (2020) Optimal sizing and location of solar capacity in an electrical network using lightning search algorithm. Electric Power Components and Systems 1-14

87. Lu Y, Zhou Y (2017) Design of multilayer microwave absorbers using hybrid binary lightning search algorithm and simulated annealing. Prog Electromagn Res 78:75-90

88. Sode-Yome A, Mithulananthan N, Lee KY (2007) A comprehensive comparison of facts devices for enhancing static voltage stability. In: 2007 IEEE power engineering society general meeting, IEEE, pp 1-8

89. Sirjani R, Okonkwo EC (2016) A new wind power model using the lightning search algorithm. In: 2016 HONET-ICT, IEEE, pp 93-97

90. Sarker MR, Mohamed A, Mohamed R (2017) Improved proportional-integral voltage controller for a piezoelectric energy harvesting system converter utilizing lightning search algorithm. Ferroelectrics 514:123-145

91. Syed Nasir S, Jamian J, Mustafa M (2018) Minimization of harmonic distortion impact due to large-scale fast charging 
station using modified lightning search algorithm and paretofuzzy synergistic approach. IEEJ Transactions on Electrical and Electronic Engineering 13:815-822

92. Elsisi M, Abdelfattah H (2020) New design of variable structure control based on lightning search algorithm for nuclear reactor power system considering load-following operation. Nucl Eng Technol 52:544-551

93. Ali JA, Hannan MA, Mohamed A (2016) Optimized speed controller for induction motor drive using quantum lightning search algorithm. In: 2016 IEEE international conference on power and energy (PECon), pp 511-516

94. Abualigah L, Shehab M, Alshinwan M, Alabool H, Abuaddous HY, Khasawneh AM, Al Diabat M (2020) Ts-gwo: Iot tasks scheduling in cloud computing using grey wolf optimizer. In: Swarm intelligence for cloud computing, Chapman and Hall/CRC, pp 127-152

95. Khasawneh AM, Kaiwartya O, Abualigah LM, Lloret $\mathrm{J}$ et al (2020) Green computing in underwater wireless sensor networks pressure centric energy modeling. IEEE Systems Journal

96. Safaldin M, Otair M, Abualigah L (2020) Improved binary gray wolf optimizer and svm for intrusion detection system in wireless sensor networks. Journal of Ambient Intelligence and Humanized Computing 1-18

97. Liu W, Huang Y, Zong X, Shi H, Ye Z, Wei S (2018) Application of lightning search algorithm in localization of wireless sensor networks. In: 2018 IEEE 4th international symposium on wireless systems within the international conferences on intelligent data acquisition and advanced computing systems (IDAACS-SWS), IEEE, pp 57-61

98. Asvany T, Amudhavel J, Sujatha P (2017) Lightning search algorithm for solving coverage problem in wireless sensor network. Advances and Applications in Mathematical Sciences 17:113-127

99. Wang C, Cai W, Ye Z, Yan L, Wu P, Wang Y (2018) Network intrusion detection based on lightning search algorithm optimized extreme learning machine. In: 2018 13th international conference on computer science education (ICCSE), pp 1-5

100. Mirjalili S, Lewis A (2016) The whale optimization algorithm. Adv Eng Softw 95:51-67

101. Abualigah L, Shehab M, Diabat A, Abraham A (2020) Selection scheme sensitivity for a hybrid salp swarm algorithm: analysis and applications. Engineering with Computers 1-27

102. Mirjalili S (2016) Dragonfly algorithm: a new meta-heuristic optimization technique for solving single-objective, discrete, and multi-objective problems. Neural Comput \& Applic 27:1053-1073

103. Abualigah L, Shehab M, Alshinwan M, Mirjalili S, Abd Elaziz M (2020) Ant lion optimizer: a comprehensive survey of its variants and applications. Archives of Computational Methods in Engineering

104. Abualigah L, Diabat A (2020) A comprehensive survey of the grasshopper optimization algorithm: results, variants, and applications. Neural Comput \& Applic 1-24
105. Abualigah L (2020) Group search optimizer: a nature-inspired meta-heuristic optimization algorithm with its results, variants, and applications. Neural Comput \& Applic 1-24

106. Shehab M, Alshawabkah H, Abualigah L, Nagham A-M (2020) Enhanced a hybrid moth-flame optimization algorithm using new selection schemes. Engineering with Computers 1-26

107. Abualigah L, Diabat A, Geem ZW (2020) A comprehensive survey of the harmony search algorithm in clustering applications. Appl Sci 10:3827

108. Abualigah LM, Khader AT, Hanandeh ES (2019) Modified krill herd algorithm for global numerical optimization problems. In: Advances in nature-inspired computing and applications, Springer, pp 205-221

109. Heidari AA, Mirjalili S, Faris H, Aljarah I, Mafarja M, Chen H (2019) Harris hawks optimization: algorithm and applications. Futur Gener Comput Syst 97:849-872

110. He Q, Wang L (2007) An effective co-evolutionary particle swarm optimization for constrained engineering design problems. Eng Appl Artif Intell 20:89-99

111. Lee KS, Geem ZW (2005) A new meta-heuristic algorithm for continuous engineering optimization: harmony search theory and practice. Comput Methods Appl Mech Eng 194:3902-3933

112. Mezura-Montes E, Coello CAC (2008) An empirical study about the usefulness of evolution strategies to solve constrained optimization problems. Int J Gen Syst 37:443-473

113. Gandomi AH, Yang X-S, Alavi AH, Talatahari S (2013) Bat algorithm for constrained optimization tasks. Neural Comput \& Applic 22:1239-1255

114. Mirjalili S (2015) Moth-flame optimization algorithm: a novel nature-inspired heuristic paradigm. Knowl-Based Syst 89:228249

115. Long W, Wu T, Liang X, Xu S (2019) Solving high-dimensional global optimization problems using an improved sine cosine algorithm. Expert Syst Appl 123:108-126

116. Mahdavi M, Fesanghary M, Damangir E (2007) An improved harmony search algorithm for solving optimization problems. Appl Math Comput 188:1567-1579

117. Huang F-Z, Wang L, He Q (2007) An effective co-evolutionary differential evolution for constrained optimization. Appl Math Comput 186:340-356

118. He Q, Wang L (2007) A hybrid particle swarm optimization with a feasibility-based rule for constrained optimization. Appl Math Comput 186:1407-1422

119. Rashedi E, Nezamabadi-Pour H, Saryazdi S (2009) Gsa: a gravitational search algorithm. Inf Sci 179:2232-2248

120. Kaveh A, Talatahari S (2010) An improved ant colony optimization for constrained engineering design problems. Eng Comput 27:155-182

Publisher's note Springer Nature remains neutral with regard to jurisdictional claims in published maps and institutional affiliations. 


\section{Affiliations}

Laith Abualigah $^{1}$ (D) - Mohamed Abd Elaziz ${ }^{2,3} \cdot$ Abdelazim G. Hussien $^{4} \cdot$ Bisan Alsalibi $^{5}$.

Seyed Mohammad Jafar Jalali ${ }^{6}$ - Amir H. Gandomi ${ }^{7}$

Mohamed Abd Elaziz

sabd_el_aziz_m@yahoo.com

Abdelazim G. Hussien

aga08@fayoum.edu.eg

Bisan Alsalibi

bisan.salibi@usm.my

Seyed Mohammad Jafar Jalali

sjalali@deakin.edu.au

Amir H. Gandomi

Amirhossein.Gandomi@uts.edu.au

1 Faculty of Computer Sciences and Informatics, Amman Arab University, Amman 11953, Jordan

2 Department of Mathematics, Faculty of Science, Zagazig University, Zagazig, Egypt

3 School of Computer Science and Technology, Wuhan University of Technology, Wuhan, China

4 Faculty of Science, Fayoum University, Al Fayyum, Egypt

5 School of Computer Sciences, Universiti Sains Malaysia, USM, 11800 George Town, Malaysia

6 Institute for Intelligent Systems Research and Innovation (IISRI), Deakin University, Waurn Ponds, VIC 3216, Australia

7 Faculty of Engineering and Information Technology, University of Technology Sydney, Ultimo, NSW 2007, Australia 